\title{
UEFA expert group statement on nutrition in elite football. Current evidence to inform practical recommendations and guide future research
}

\author{
James Collins, ${ }^{1,2}$ Ronald John Maughan, ${ }^{3}$ Michael Gleeson, ${ }^{4}$ Johann Bilsborough, ${ }^{5,6}$ \\ Asker Jeukendrup ${ }^{4,7}$ James P Morton, ${ }^{8}$ S M Phillips (1), ${ }^{9}$ Lawrence Armstrong, ${ }^{10}$

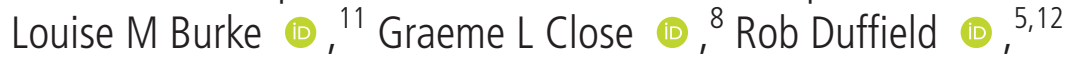 \\ Enette Larson-Meyer, ${ }^{13}$ Julien Louis (1) , ${ }^{8}$ Daniel Medina, ${ }^{14}$ Flavia Meyer (1) , ${ }^{15}$ \\ Ian Rollo, ${ }^{4,16}$ Jorunn Sundgot-Borgen (ㄷ, ${ }^{17}$ Benjamin T Wall, ${ }^{18}$ Beatriz Boullosa, ${ }^{19}$ \\ Gregory Dupont $\left(10,{ }^{8}\right.$ Antonia Lizarraga, ${ }^{20}$ Peter Res, ${ }^{21}$ Mario Bizzini, ${ }^{22}$ \\ Carlo Castagna (1) , 23,24,25 Charlotte M Cowie, ${ }^{26,27}$ Michel D'Hooghe, ${ }^{27,28}$ \\ Hans Geyer, ${ }^{29}$ Tim Meyer (1), ${ }^{27,30}$ Niki Papadimitriou, ${ }^{31}$ Marc Vouillamoz, ${ }^{31}$ \\ Alan McCall (1) 2,12,32
}

For numbered affiliations see end of article.

\section{Correspondence to} Dr Alan McCall, Arsenal Performance and Research team, Arsenal Football Club, London, UK;

amccall@arsenal.co.uk

Accepted 18 June 2020 Published Online First 23 October 2020

\section{Linked}

- http://dx.doi.org/10.1136/ bjsports-2019-101972

Check for updates

(C) Author(s) (or their employer(s)) 2021. No commercial re-use. See rights and permissions. Published by BMJ.

To cite: Collins J,

Maughan RJ, Gleeson M

et al. Br J Sports Med

2021:55:416-442

\section{ABSTRACT}

Football is a global game which is constantly evolving, showing substantial increases in physical and technical demands. Nutrition plays a valuable integrated role in optimising performance of elite players during training and match-play, and maintaining their overall health throughout the season. An evidence-based approach to nutrition emphasising, a 'food first' philosophy (ie, food over supplements), is fundamental to ensure effective player support. This requires relevant scientific evidence to be applied according to the constraints of what is practical and feasible in the football setting. The science underpinning sports nutrition is evolving fast, and practitioners must be alert to new developments. In response to these developments, the Union of European Football Associations (UEFA) has gathered experts in applied sports nutrition research as well as practitioners working with elite football clubs and national associations/federations to issue an expert statement on a range of topics relevant to elite football nutrition: (1) match day nutrition, (2) training day nutrition, (3) body composition, (4) stressful environments and travel, (5) cultural diversity and dietary considerations, (6) dietary supplements, (7) rehabilitation, (8) referees and (9) junior high-level players. The expert group provide a narrative synthesis of the scientific background relating to these topics based on their knowledge and experience of the scientific research literature, as well as practical experience of applying knowledge within an elite sports setting. Our intention is to provide readers with content to help drive their own practical recommendations. In addition, to provide guidance to applied researchers where to focus future efforts.

\section{UEFA EXPERT GROUP STATEMENT ON NUTRITION IN ELITE FOOTBALL: EXECUTIVE SUMMARY}

Football (soccer) is a global game which is constantly evolving with substantially increasing physical and technical demands of match play. Training regimens have become more demanding physically, in an attempt to prepare players to cope with these evolutions and to address individual player needs. Nutrition can play a valuable role in optimising the physical and mental performance of elite players during training and match-play, and in maintaining their overall health throughout a long season.

Good nutrition choices can support the health and performance of footballers: the type, quantity and timing of food, fluids and supplements consumed can influence players' performance and recovery during and between matches. ${ }^{12}$ However, the rapid evolution of the game itself, in addition to changes in our understanding of sports nutrition, has created uncertainty as to the appropriate nutritional decisions to make at specific moments in time and in specific contexts. In 2017, the steering committee of the current UEFA nutrition expert statement (JC, RM, JB, AMcC) committed ${ }^{3}$ to undertake an expert-led statement to update the knowledge and research about nutrition in elite football. We highlighted that the last expert-led statement on elite football nutrition had been written 11 years earlier.

While sports nutrition research since the last expert statement ${ }^{1}$ has in some instances helped to advance our knowledge and shape our practical strategies with elite footballers, the influx of new research brings with it confusion as to the relevance and veracity of current advice. It is often difficult for practitioners to interpret the available evidence and make sense of the controversies that may exist, in particular with the influx of different and opposing messages, especially from social media channels. ${ }^{4}$ In these instances, expert-led statements can be a powerful tool to aid practitioners with clarity on current research evidence.

This executive summary of the full scientific article-the 'UEFA expert group statement'provides a series of infographics illustrating important practical applications and insights that are intended to help practitioners take away some key points from the full article. We strongly advise practitioners to read and digest the full article and 
not only the practical infographic summary. This will ensure a more in-depth appreciation of the scientific evidence and the critical appraisals from the many experts involved which accompany the recommendations, in addition to understanding the fuller context and how to apply in their own practice.

In this expert group statement, nine specific topics have been identified: (1) match day (MD) nutrition, (2) training day nutrition, (3) body composition, (4) stressful environments and travel, (5) cultural diversity and dietary considerations, (6) dietary supplements, (7) rehabilitation, (8) referees and (9) junior high-level players. Our narrative synthesis and critical appraisal takes into account the diversity of the footballing community, including both male and female players, outfield players and goalkeepers and match officials.

As part of this process, UEFA has consulted with many specialists from the game to provide insights on the current role and future direction of nutrition in football. We often hear from the scientific community of the importance of sports science within football, but too often the voices of coaches are not heard in best practice guidelines, when they could offer valuable insight. Part of this executive summary includes an editorial by one of the world's most iconic coaches, Arsène Wenger, who discusses the coach's perspective on nutrition within the current footballing landscape and looks to the future of nutrition for players and teams around the world. We also have a brief 'warm up' to this UEFA expert statement from Marc Vouillamoz, UEFA Head of Medical and Antidoping and an editorial from Dr Tim Meyer, Chairman of the UEFA Medical Committee: these provide important antidoping and medical perspectives on the importance of nutrition in football.

As you will read in the full article and is evident throughout the series of infographics, the UEFA expert statement advocates an evidence-based approach to nutrition, and emphasises a 'food first' philosophy (ie, prioritising food over supplements to meet nutrient requirements) as being fundamental to ensure effective player support. It is crucial that clubs and national associations, where possible, use the services of qualified professionals with nutrition-related undergraduate degrees, postgraduate qualifications in sport and exercise nutrition and professional registration (depending on the country).

The expert statement process was created by a steering committee (JC, RJM, JB, AMcC) who identified the topics to be included and compiled a list of research and field-based experts. Expert group members $(\mathrm{n}=31$ in total) included basic and applied researchers $(n=6)$ and field-based practitioners $(n=5)$; the majority $(n=14)$ had a background of both research and field-based practice and six were UEFA Medical Committee members. It is intended that this narrative synthesis will provide readers with the scientific underpinning to inform their practical recommendations and strategies. In addition, we aim to guide applied researchers to focus their future efforts in regards to elite football nutrition research.

\section{INTRODUCTION}

Good nutrition choices can support the health and performance of footballers: the type, quantity and timing of food, fluids and supplements consumed can influence players' performance and recovery during and between matches. ${ }^{12}$ However, the rapid evolution of the game itself, in addition to changes in our understanding of sports nutrition, creates uncertainty as to the appropriate nutritional decisions to make at specific moments in time and in specific contexts.
The physical and technical demands of elite football have increased in recent years, ${ }^{56}$ as have the financial implications of winning or losing. Training regimens have been adapted accordingly; they are more demanding and more sophisticated as they prepare players to cope with the evolution in match demands. Congested match schedules have been suggested to increase the risk of injury to players. ${ }^{78}$ Kick-off times have become more variable, with teams required to play early or late to accommodate television schedules. The travel required to compete in multiple domestic and international tournaments adds to the demands on players, with different logistical challenges depending on the geographical location. The reality being that the best players play the most often. Moreover, football truly is a global game ${ }^{9}$ : frequent intracontinental and intercontinental matches and the migration of foreign players both result in greater cultural diversity and associated nutritional considerations.

The exponential rise in sports nutrition research in recent years has advanced our knowledge and expertise, but brings with it confusion as to what is actually sound advice. Those providing sports science support at elite level should follow an evidence-based approach, ${ }^{10}$ but it is often difficult for practitioners to interpret the available evidence and make sense of the controversies that may exist in particular with the influx of noise (ie, flawed messages) from social media channels. ${ }^{4}$ This, in part, reflects the limitations of our current knowledge: we know, for example, that the recommended dietary allowance (RDA) is the average daily dietary intake that suffices to meet the nutrient requirements of nearly all (98\%) healthy people, but it is unclear how these values should be applied in the assessment of dietary intakes of footballers and other athletic populations. We should also recognise that much of the available data on dietary intakes is flawed, and probably does not reflect the true nutrient and energy intake of the populations that have been studied. ${ }^{11}$ Expert-led statements can be a powerful tool to aid practitioners in these instances, but although there are recent examples in different sporting situations, ${ }^{212}$ the most recent example of this in football-specific nutrition was a consensus published over a decade ago.

The aim of this paper is to provide a narrative synthesis of the current evidence relating to various topics in elite football nutrition and in doing so, this manuscript is targeted at researchers, scientists and practitioners with scientific knowledge and understanding.

This UEFA expert group statement endorses and supports a 'food first' philosophy. This aims to establish best practice recommendations and represents an important next step in supporting the growth of nutrition within football. It is crucial that clubs and national associations, where possible, use the services of qualified professionals with nutrition-related undergraduate degrees, postgraduate qualifications in sport and exercise nutrition and professional registration (depending on the country); for simplicity, we use the term 'sports nutritionist' throughout.

We note several limitations to the evidence base from which recommendations of best practice can be reached:

1. There is little research specific to football, and the laboratory models that have been developed to simulate the game generally fail to replicate the demands of match play. As such, results need to be extrapolated from different sports and simpler exercise protocols.

2. Those studies that have used football as a model have been done with players engaged at recreational level. There is very little information derived from studies of elite players. 
3. Many of the methods that have been used to assess the dietary habits of players and their nutritional status are fundamentally flawed and do not provide reliable information.

4. As with all studies, publication bias can increase the risk of a skewed picture of the efficacy of nutrition interventions, especially those involving the use of supplements. Studies that do not produce a positive outcome are less likely to be published than those that produce positive results.

We also recognise that, despite the great popularity of women's football, there are few relevant studies. Nutritional needs and practices likely vary more within one sex than between sexes: the sex of the player is therefore another factor to be taken into account when considering the needs of an individual player.

\section{EXPERT GROUP STATEMENT PROCESS}

A steering committee (JC, RJM, JB, AMcC) identified the topics to be included and compiled a list of research and field-based experts. Expert group members $(n=31$ in total) including basic and applied researchers $(n=6)$ and field-based practitioners $(n=5)$; the majority $(n=14)$ had a background of both research and field-based practice and six were UEFA Medical Committee members. An outline of the expert group statement was agreed by all members: the authors were asked to focus on what is currently known from scientific research combined with their practical knowledge and expertise. First drafts of each section were collated by the steering committee to form the basis of the first full draft. This was circulated to all expert group members: the applied researchers focused on the narrative synthesis of the scientific research literature and the practitioners on the ecological validity in the football setting. Comments were collated and changes made before further review by the expert group. This process continued until agreement was reached on the specific sections and recommendations included (the whole process lasted from December 2017 to December 2019). A meeting between the steering committee and UEFA Medical Committee members (June 2019) was held to discuss and agree on any final amendments or additions that needed to be made and these were then circulated to the expert group for their review. This resulted in one further draft version before finalisation (December 2019).

The key recommendations are aimed at both male and female professional players, the majority of whom will be training and playing full time. Distinctions between male and female players are clearly made where appropriate; unless otherwise stated, the key recommendations apply to both sexes. Additional sections focus on elite referees and elite junior players (ie, players aged under 18 years and belonging to a professional football academy and training full-time).

\section{EXPERT GROUP TOPIC 1: MATCH DAY NUTRITION Match play demands}

During a football match, players engage in a variety of activities from walking to sprinting, changing direction, jumping and striking the ball, in addition to contact with opposition players. In outfield players, heart rate is maintained at an average of $85 \%$ of maximum and the average relative exercise intensity at $70 \%$ of maximal oxygen uptake $\left(\mathrm{VO}_{2} \max \right)$ over the duration of the match, ${ }^{13}$ equating to an energy expenditure of $\sim 1300$ $1600 \mathrm{kcal}^{14}{ }^{15}$ whereby carbohydrates (CHO) contribute about $60 \%-70 \%$ of the total energy supply. ${ }^{15}$ The total MD energy expenditure has been estimated at $\sim 3500 \mathrm{kcal} .{ }^{16}$ To date, no studies have been performed to assess the physiological demands or fatigue responses of goalkeepers specifically. ${ }^{17}$ Limited research suggests that goalkeepers perform extended
( 45-60 min) pre-match warm-ups and, while they cover less total distance and perform fewer high-intensity activities, they are rarely substituted and need to be prepared for a full 90-120 min match. ${ }^{17}$ The physical and technical demands of match play for elite outfield male footballers have increased substantially in recent years, ${ }^{56}$ likely as a result of tactical modifications. ${ }^{6}$ While the total distance covered decreased by a trivial magnitude of $2 \%(10679 \pm 956$ vs $10881 \pm 885 \mathrm{~m})$ between 2006 and 2013, high-intensity and sprint running have increased substantially, with high-intensity running distance and high-intensity actions up by $\sim 30 \%(890 \pm 299$ vs $1151 \pm 337 \mathrm{~m})$ and $\sim 50 \%(118 \pm 36$ vs $176 \pm 46)$, respectively. ${ }^{5}$ Over that same period of time, sprint distance and number of sprints rose by $\sim 35 \%$ (232 \pm 114 vs $350 \pm 139 \mathrm{~m})$ and $\sim 85 \%$ (31 \pm 14 vs $57 \pm 20)$, respectively. This trend is seen in all outfield positions (central defenders, fullbacks, central midfielders, wide midfielders and attackers). ${ }^{5}$ Evolutions in technology have revealed that players make more passes ( $35 \pm 17$ vs $25 \pm 13$ ), and that these are more successful $(83 \% \pm 10 \%$ vs $76 \pm 13 \%) .5$ These increased physical and potentially technically demanding (eg, cognitive) tasks make effective nutritional strategies even more important.

Research on elite female players is sparse. The available evidence highlights that elite female players (international level) cover approximately the same average total distance as their male counterparts, but they run less at high speeds. ${ }^{18}$ An important point to note is that no study has compared the high-speed or sprinting demands of male and female players relative to individual maximum speed. The use of absolute speed thresholds does not reflect differences in the maximum speed of individual players ${ }^{19}$ or gender differences.

\section{Preparation for match play (carbohydrates and fluids)}

$\mathrm{CHO}$ is the primary fuel for muscle during high-intensity activities; it is therefore a key macronutrient when preparing players for match play. On the day prior to a match (MD-1), training is usually light and $\mathrm{CHO}$ intake should be at least $6-8 \mathrm{~g} / \mathrm{kg}$ body mass (BM) to elevate muscle and liver glycogen stores. ${ }^{20}$ While the glycogen cost of elite match play in either male or female players is not yet known, ${ }^{21}$ data from a friendly match involving lower division Danish male players demonstrate that approximately $50 \%$ of muscle fibres are classified as empty or partially empty after match play. ${ }^{22}$ Players who begin a game with low muscle glycogen stores will cover less distance and much less at high speed, particularly in the second half, than those who have ensured adequate glycogen stores. ${ }^{23}$ Where the match schedule consists of congested fixtures (eg, domestic fixtures, European competition, international games), $\mathrm{CHO}$ intake should be maintained within this range $(6-8 \mathrm{~g} / \mathrm{kg} \mathrm{BM} /$ day) for the $48-72$ hours between games to promote adequate glycogen storage. The reality is that players often consume less than this and daily intake may be closer to about $4 \mathrm{~g} / \mathrm{kg} \mathrm{BM} .{ }^{16} \mathrm{~A}$ conscious focus on the intake of $\mathrm{CHO}$-rich foods is needed, with increased $\mathrm{CHO}$ intake at the cost of fat intake (and possibly protein intake) to ensure adequate glycogen restoration.

Maintaining an appropriate hydration status will support players' health and performance. ${ }^{24}$ Sweating is the primary mechanism to dissipate the metabolic heat generated during football training and match play in both cool and hot environments. ${ }^{25} 26$ Players should aim to start the match fully hydrated: daily BM measurements, ${ }^{27}$ degree of thirst, ${ }^{28}$ urine colour, ${ }^{29}$ osmolality and urine-specific gravity can be useful indicators of hydration status. ${ }^{30}$ A urine osmolality of $<700 \mathrm{mOsmol} / \mathrm{kg}$ or a specific gravity of $<1.020$ suggests euhydration and $>900 \mathrm{mOsmol} /$ 
$\mathrm{kg}$, hypohydration, although individual variability is present. ${ }^{31}$ For games with an early kick-off, the day prior to the match represents a key opportunity to optimise the players' hydration status for the match the following day.

It has become popular in recent years to suggest that the only advice relating to hydration that is either necessary or appropriate for those involved in sport is to drink according to the dictates of thirst. ${ }^{32}$ This may not be appropriate in many team sport contexts, including football training and match play. ${ }^{33}$ The availability of fluids and the sensation of thirst may not coincide, and some forward planning (eg, understanding individual sweat losses, developing individualised hydration plans, alongside player education) can ensure that each player's hydration needs are met.

\section{Pre-match (CHO and fluids)}

On MD itself, $\mathrm{CHO}$ intake is again one of the most important considerations. Within an overall guideline of $6-8 \mathrm{~g} / \mathrm{kg} \mathrm{BM}$ $\mathrm{CHO}$ per day, it is recommended that players consume a $\mathrm{CHO}-$ rich meal (1-3 g/kg BM) 3-4 hours before kick-off to ensure that they begin the match with adequate glycogen stores. The pre-match meal is of particular importance for the promotion of liver glycogen stores, given that such stores can be reduced by about $50 \%$ after an overnight fast. ${ }^{34}$ This may be particularly important for matches with a lunchtime kick-off, and it highlights the importance of optimising nutritional preparation during the day prior to the match. The pre-match meal should be easily digestible to reduce the risk of gastrointestinal problems (eg, reflux, discomfort). The pre-match meal should also make players 'feel better' ${ }^{35}$ so comfort should be considered, rather than rigid strategies focused solely on meeting $\mathrm{CHO}$ intake guidelines. Player 'rituals' can be strongly held and education combined with practising pre-match fuelling in training or lower priority matches, can be an important tool to optimise glycogen stores and player readiness for match play.

Data from many studies suggest that high $\mathrm{CHO}$ intakes before and during a match can delay fatigue ${ }^{36}$ and enhance the capacity for intermittent high-intensity exercise. ${ }^{37} 38$ Benefits of prematch meals may extend to players' technical performance. For example, increased dribbling speed was observed when professional youth footballers consumed a larger breakfast (500 vs 250 kcal, with 60\% CHO) 135 min before a match. ${ }^{39}$

Finally, players should aim to start the match euhydrated by ingesting $5-7 \mathrm{~mL} / \mathrm{kg} \mathrm{BM}$ of fluid in the $2-4$ hours prior to kick-off. ${ }^{40}$ This allows time for excess fluid to be voided prior to exercise, targeting a urine that is pale yellow in colour. ${ }^{29}$

\section{During match play (CHO and fluids)}

Sufficient $\mathrm{CHO}$ and fluid intake are the two main nutritional considerations during match play. Research evidence typically shows performance benefits in protocols simulating football matches when $\mathrm{CHO}$ is consumed during exercise at rates of $\sim 30-60 \mathrm{~g} /$ hour, ${ }^{41-44}$ or when $60 \mathrm{~g}$ is consumed before each half. $^{45}$ It is therefore recommended that $\sim 30-60 \mathrm{~g}$ CHO is consumed after warm-up and again at half-time to meet these guidelines. $\mathrm{CHO}$ ingestion during intermittent exercise also seems to improve shooting performance, ${ }^{38} 46$ dribbling speed, ${ }^{47}$ and passing, ${ }^{46}$ although the effects on sprinting, jumping, change of direction speed and cognition are less consistent. ${ }^{3741}$ The current practices of elite players appear to be at the lower end of the $\sim 30-60 \mathrm{~g} /$ hour scale; players in the English Premier League reported mean $\mathrm{CHO}$ intakes of $32 \mathrm{~g} /$ hour just before and during a match. ${ }^{16}$ This may be attributed to the match rules, which limit intake to warm-up and half-time (see below) and to the fear or actual experience of gastrointestinal problems during matches. This is a situation where sports foods (eg, CHO drinks, gels) can provide a preferred delivery option, to minimise these gastrointestinal issues. Stoppages during the match may also provide a valuable opportunity for players with increased $\mathrm{CHO}$ and/or fluid needs or for the whole team in hot conditions (see the section 'Expert group topic 4' on stressful environments).

Receptors in the oral cavity detect $\mathrm{CHO}$ consumed during exercise and exert central effects that may reduce the perception of effort. ${ }^{49} \mathrm{CHO}$ mouth rinsing has been shown to increase self-selected jogging speed with likely benefits in sprint performance during intermittent exercise. ${ }^{50}$ The implications for football are still unclear, ${ }^{51}$ but the use of $\mathrm{CHO}$ mouth rinsing during breaks in match play (eg, half-time, extra-time, injury stoppages, medical breaks) could potentially enhance performance in situations where $\mathrm{CHO}$ consumption is limited by gastrointestinal concerns. On the other hand, it has been noted in recent tournaments that some players appear to misunderstand the mouth rinsing strategy and spit out the $\mathrm{CHO}$-containing fluid even when there are no gastrointestinal problems. This may be partly due to the design of a scientific investigation in which there is an interest in distinguishing between the central nervous system and muscle fuel effects of $\mathrm{CHO}$ intake during exercise. Indeed, swallowing the drink following a $\sim 5 \mathrm{~s}$ exposure in the mouth allows both effects to occur simultaneously; this will be important in scenarios in which a player's workload is high and CHO supplies may become limiting. It should be remembered that matches can extend to extra time and penalty shoot-outs where both the brain and muscle may benefit from additional fuel support and activation.

Sweat rates vary greatly between players and are primarily influenced by the intensity of exercise, environmental conditions and acclimation status. ${ }^{52}$ During training and matches sweat rates in male players have been reported to range from 0.5 to $2.5 \mathrm{~L} /$ hour $^{265354}$ : lower values are generally reported in female players because of lower BM and lower absolute work rates. ${ }^{55-57}$

Sweat also contains electrolytes, primarily sodium, concentrations of which vary substantially between players. ${ }^{54}$ Mechanisms by which sweating-induced hypohydration might impair football performance are not completely elucidated, but may include increased cardiovascular strain, ${ }^{58}$ impaired cognitive function, ${ }^{59}$ increased perception of effort, ${ }^{60}$ reduced physical function ${ }^{60}$ and reduced technical skills. ${ }^{61}$ It is likely that individual players may be more or less sensitive to hypohydration during exercise. Therefore as a guide, players should aim to drink sufficient fluids to prevent a deficit of $>2 \%-3 \%$ of pre-exercise BM during exercise, ${ }^{39} 62$ while avoiding gains in BM (hyperhydration) and also ensuring their fuel needs are met. ${ }^{38}$

Both hydration and $\mathrm{CHO}$ intake may require special attention in matches where extra time $(2 \times 15 \mathrm{~min})$ is played. All match nutrition strategies, including the use of supplements (eg, sports foods), should be practised in training and minor matches to allow individualised protocols to be developed and to identify adverse effects in players, as well as allowing them the opportunity to become accustomed to any potential adverse effects, with minimal impact on important match performance.

\section{Recovery from match play (CHO, fluids, protein)}

A primary objective following a competitive match is to reduce the time needed to fully recover. ${ }^{63}$ One essential goal is to rapidly replenish $\mathrm{CHO}$ stores. Postmatch meals and snacks should target a CHO intake of $\sim 1 \mathrm{~g} / \mathrm{kg} \mathrm{BM} /$ hour for 4 hours. ${ }^{64}$ This is usually 
facilitated by the consumption of drinks and snacks in the changing rooms followed by post-match meals at the stadium, during travel and at home. Sports foods may provide a preferred option to supply macronutrients, especially to achieve $\mathrm{CHO}$ guidelines when appetite may be reduced or when sourcing food away from the home environment. Players should also aim to reduce any fluid and electrolyte deficit soon after the match ${ }^{65}$; however, in most situations there is sufficient opportunity and time to restore euhydration and electrolyte balance with normal eating/drinking practices, while also meeting other recovery objectives. ${ }^{63} 65$

Elite football players may not achieve $\mathrm{CHO}$ targets in recovery from evening games, ${ }^{66}$ suggesting suboptimal glycogen resynthesis patterns, the result of which is likely problematic for recovery and preparation during congested fixture schedules. As discussed above, daily $\mathrm{CHO}$ intake in the range of $6-8 \mathrm{~g} / \mathrm{kg}$ $\mathrm{BM}$ in the 24 hours following a game $(\mathrm{MD}+1)$ will continue to replenish glycogen stores and this intake should be maintained for up to 48-72 hours after the match during congested fixture schedules. Higher intakes and additional nutritional strategies may be required when players report symptoms of muscle soreness and damage, as glycogen synthesis is impaired in the presence of muscle damage. ${ }^{67-69}$ To optimise protein synthesis for repair and adaptation, meals and snacks should be scheduled to achieve intakes of $20-25 \mathrm{~g}$ of (high-quality) protein at 3-4 hour intervals. ${ }^{70-72}$ Furthermore, there is emerging evidence that consuming 30-60 g of casein protein prior to sleep can enhance overnight protein synthesis. $^{73}$

Although postexercise protein intake undoubtedly increases protein synthetic rates and net protein accretion, this is a slow process and there is little evidence of acute improvements in muscle function. ${ }^{74}$ Some studies have reported reductions in muscle soreness with postexercise intake of protein or branched chain amino acids, ${ }^{75}$ but the overall effects are small. Consuming polyphenol-rich tart cherry juice has become a popular intervention to accelerate muscle recovery in different sports, ${ }^{76} 77$ but recent investigation in football did not show improved recovery markers of function or subjective soreness. ${ }^{78}$ Therefore, the available evidence does not support its specific use in football. Reducing exercise-induced muscle inflammation and free radical production, particularly with large doses of individual antioxidant vitamins $\mathrm{C}$ and $\mathrm{E}$, may interfere with adaptive processes in muscle and is therefore discouraged. ${ }^{79}$

\section{Alcohol}

Some players may drink alcohol in social settings with teammates, friends and family, or as a means to relieve stress, anxiety or depression; this is particularly likely to occur after a match. ${ }^{63}$ Occasional intake of small amounts (no more than 2 units/day) of alcohol is not harmful, but alcohol use can interfere with recovery by impairing liver and glycogen resynthesis, ${ }^{80}$ muscle myofibrillar protein synthesis ${ }^{81}$ and rehydration. ${ }^{82}$ Drinking large doses of alcohol can also impair next-day countermovement jump performance ${ }^{83}$ and also directly suppress a wide range of immune responses ${ }^{84}$ and players should therefore minimise or avoid intake during key periods of training and match play when recovery is a priority.

\section{EXPERT GROUP TOPIC 2: TRAINING DAY NUTRITION} Overview of training calendar, objectives and training load The football season is typically categorised into three distinct phases: preseason, in-season and off-season (see table 1). Despite more than four decades of research examining the physical demands of match play, ${ }^{6586}$ detailed analysis of the customary training loads of elite footballers is comparatively recent and remains limited. ${ }^{20}$ 87-89 These data demonstrate that training loads are lower than those experienced in match play, including total distance $\left(<7 \mathrm{vs} \sim 10-13 \mathrm{~km}\right.$ ), ${ }^{20}$ high-speed running distance $(<300$ vs $>900 \mathrm{~m}),{ }^{90}$ sprint distance $(<150 \text { vs }>200 \mathrm{~m})^{91}$ and average speed $(<80$ vs $\sim 100-120 \mathrm{~m} / \mathrm{min}){ }^{20}$ Absolute daily training loads depend on many factors including phase of the season, ${ }^{89}$ player position, ${ }^{89}$ coaching philosophy, ${ }^{88} 89$ frequency of games, ${ }^{92}$ player starting status ${ }^{88}$ and player-specific training goals such as manipulation of body composition ${ }^{93}$ or rehabilitation from injury. ${ }^{94}$

In the traditional in-season scenario of one match per week, players may complete four to five 'on-field' training sessions where the absolute training load is likely to be periodised across the weekly microcycle according to the proximity and importance of the game itself. ${ }^{20}$ Players may also undertake additional 'off-field' sessions, such as strength training. The aim is to stimulate both aerobic and strength adaptations while simultaneously rehearsing technical skills and tactics. It is noteworthy, however, that gym and field-based training sessions may not always be delivered in a systematic and structured sequence. ${ }^{95}$ The order of these can influence players' habitual macronutrient intake and the magnitude of the strength adaptations induced. ${ }^{96}$ Both absolute daily intake and distribution of macronutrient intake have the capacity to affect training performance and recovery and to modulate training adaptations.

\section{Carbohydrate requirements for training}

Given the role of muscle and liver glycogen in supporting energy production during match play, ${ }^{22}$ it is important to consider their contribution to training goals. Unfortunately, the lack of specific data on muscle glycogen utilisation during typical fieldbased football training sessions makes it difficult to develop clear guidelines on the $\mathrm{CHO}$ requirements for training ${ }^{97}$ other than to suggest that they differ from the requirements for match play. Some information can be gleaned from the investigation of energy expenditure in English Premier League players during a 7-day in-season microcycle consisting of two games and five training days. ${ }^{16}$ The mean daily expenditure of outfield players was assessed at $\sim 3500 \mathrm{kcal} / \mathrm{day},{ }^{16}$ with goalkeepers' energy expenditure being $\sim 600 \mathrm{kcal} /$ day less. ${ }^{98}$ In these studies, the mean daily energy intake reported by players was comparable to energy expenditure, and BM did not change during the assessment period. Players reported an adjustment of daily $\mathrm{CHO}$ intake according to the perceived load, whereby $\sim 4$ and $6 \mathrm{~g} / \mathrm{kg}$ $\mathrm{BM}$ were consumed on training and MDs, respectively. Nonetheless, given the importance of muscle glycogen for preparation and recovery from match play, it is suggested that players should increase $\mathrm{CHO}$ intake on MD-1, MD and MD +1 to between 6 and $8 \mathrm{~g} / \mathrm{kg}$ BM. However, even at $\sim 8 \mathrm{~g} / \mathrm{kg} \mathrm{BM}$, muscle glycogen content in type II fibres may not be completely restored 48 hours after a match. ${ }^{99}$

Alternatively, given the lower absolute daily loads on typical training days (ie, one session per day in a one game per week microcycle) coupled with the fact that players typically do not perform any additional structured training outside of the club, daily intakes ranging from 3 to $6 \mathrm{~g} / \mathrm{kg} \mathrm{BM}$ may be sufficient to promote fuelling and recovery. In accordance with these lower absolute loads, it is unlikely that most players require $\mathrm{CHO}$ intake during training. ${ }^{16}$ However, this may depend on the duration and intensity of the training session, the timing of training in relation to the last meal and the potential benefits of practising 
Typical daily external training

load parameters

(as quantified during pitch-

\begin{tabular}{|c|c|c|c|c|c|}
\hline Training scenario & Training objectives & $\begin{array}{l}\text { Desired training } \\
\text { adaptations }\end{array}$ & $\begin{array}{l}\text { (as quantified during pitch- } \\
\text { based training according to } \\
\text { GPS; HSR } \geq 19.8 \mathrm{~km} / \mathrm{hour} \text { ) }\end{array}$ & $\begin{array}{l}\text { Suggested daily } \\
\text { CHO range }\end{array}$ & Comments \\
\hline Preseason training & $\begin{array}{l}\text { To improve players' physical/ } \\
\text { mental/tactical qualities } \\
\text { To prepare players for a full } \\
\text { playing season } \\
\text { To avoid injury and illness }\end{array}$ & $\begin{array}{l}\text { Increase aerobic } \\
\text { and anaerobic } \\
\text { fitnessIncrease lean } \\
\text { mass/reduce fat } \\
\text { mass } \\
\text { Increase/maximise } \\
\text { strength, speed, } \\
\text { power for } \\
\text { performance and } \\
\text { injury prevention }\end{array}$ & $\begin{array}{l}\text { Duration: } 60-180 \mathrm{~min} \\
\text { Total distance: } 3-12 \mathrm{~km} \\
\text { HSR: }>400 \mathrm{~m}\end{array}$ & $4-8 \mathrm{~g} / \mathrm{kg} \mathrm{BM}$ & $\begin{array}{l}\text { Suggested range accommodates likely } \\
\text { variations in loads (eg, potential twice } \\
\text { per day sessions, recovery days) as } \\
\text { well as individual training goals (eg, } \\
\text { manipulation of body composition to } \\
\text { accommodate weight loss and fat loss } \\
\text { or weight gain and lean mass gain). } \\
\text { For example, twice per day training } \\
\text { structures would likely require higher } \\
\text { CHO intakes (eg, } 6-8 \mathrm{~g} / \mathrm{kg} \text { BM/day), } \\
\text { whereas lower absolute intakes may be } \\
\text { required where players are aiming for } \\
\text { body fat loss or training intensity and } \\
\text { duration is reduced (eg, } 4-6 \mathrm{~g} / \mathrm{kg} \mathrm{BM/} \\
\text { day). }\end{array}$ \\
\hline $\begin{array}{l}\text { In-season training } \\
\text { (one game per } \\
\text { week) }\end{array}$ & $\begin{array}{l}\text { To maintain physical } \\
\text { qualities (and improve } \\
\text { where possible/appropriate) } \\
\text { To keep players injury and } \\
\text { illness free } \\
\text { To practise MD nutrition } \\
\text { strategies }\end{array}$ & $\begin{array}{l}\text { Maintain aerobic } \\
\text { and anaerobic } \\
\text { fitness } \\
\text { At least maintain } \\
\text { strength, power, } \\
\text { speed } \\
\text { Maintain lean BM } \\
\text { Train the gut to } \\
\text { tolerate CHO during } \\
\text { football-specific } \\
\text { training (occasional } \\
\text { use) }\end{array}$ & $\begin{array}{l}\text { Duration: } 45-90 \mathrm{~min} \\
\text { Total distance: } 2-7 \mathrm{~km} \\
\text { HSR: } 0-400 \mathrm{~m}\end{array}$ & $3-8 \mathrm{~g} / \mathrm{kg} \mathrm{BM}$ & $\begin{array}{l}\text { Suggested range accommodates likely } \\
\text { variations in loads across the microcycle } \\
\text { (eg, low load days and MD- } 1 \text { CHO } \\
\text { loading protocols) as well as individual } \\
\text { training goals (eg, manipulation of } \\
\text { body composition). For example, MD-1 } \\
\text { and MD +1 would require higher CHO } \\
\text { intakes (eg, 6-8 g/kg BM/day), whereas } \\
\text { lower absolute intakes may be required } \\
\text { on other days of the week (eg, 3-6 g/kg } \\
\text { BM/day) depending on training intensity, } \\
\text { duration and player-specific goals. }\end{array}$ \\
\hline $\begin{array}{l}\text { In-season training } \\
\text { (congested fixture } \\
\text { periods) }\end{array}$ & $\begin{array}{l}\text { To avoid injury and illness } \\
\text { To accelerate recovery }\end{array}$ & $\begin{array}{l}\text { Restore muscle } \\
\text { function as quickly } \\
\text { as possible } \\
\text { Promote glycogen } \\
\text { resynthesis } \\
\text { Fluid replacement: } \\
\text { rehydration } \\
\text { Alleviate mental } \\
\text { fatigue }\end{array}$ & $\begin{array}{l}\text { Duration: }<60 \mathrm{~min} \\
\text { Total distance: }<3 \mathrm{~km} \\
\text { HSR: }<50 \mathrm{~m}\end{array}$ & $6-8 \mathrm{~g} / \mathrm{kg} \mathrm{BM}$ & $\begin{array}{l}\text { Suggested range accommodates } \\
\text { the requirement to replenish muscle } \\
\text { glycogen stores in the } 48-72 \text { hours } \\
\text { period between games. During this time, } \\
\text { it is suggested that players consistently } \\
\text { consume } \mathrm{CHO} \text { within this range so as to } \\
\text { promote glycogen availability. }\end{array}$ \\
\hline Off-season training & $\begin{array}{l}\text { To avoid detraining } \\
\text { To ensure players come back } \\
\text { ready for the demands of the } \\
\text { preseason }\end{array}$ & $\begin{array}{l}\text { Minimise the loss } \\
\text { of aerobic and } \\
\text { anaerobic capacity } \\
\text { Minimise decrements } \\
\text { in strength, power, } \\
\text { speed } \\
\text { Minimise decreases } \\
\text { in lean mass and } \\
\text { increases in fat mass }\end{array}$ & $\mathrm{N} / \mathrm{A}$ & $<4 \mathrm{~g} / \mathrm{kg} \mathrm{BM}$ & $\begin{array}{l}\text { Suggested intake accommodates the } \\
\text { cessation of normal training loads, } \\
\text { to avoid gains in fat mass. Note, for } \\
\text { players who may be undergoing higher } \\
\text { training loads (eg, off-season training } \\
\text { programmes) CHO intake should be } \\
\text { increased accordingly. }\end{array}$ \\
\hline
\end{tabular}

BM, body mass; CHO, carbohydrate; HSR, high speed running; MD, match day; N/A, not available.
CHO consumption during exercise to 'train the gut' to better absorb and tolerate intake during matches. Daily $\mathrm{CHO}$ requirements for training should operate on a sliding scale of 3-8g/ $\mathrm{kg} \mathrm{BM} /$ day depending on the specific training scenario, fixture schedule and player-specific training goals (further context is provided in table 1 ).

\section{Protein recommendations for training}

Daily football training places stress on the musculoskeletal and tendinous tissues, and there is a need to remodel and repair these protein-containing structures to maintain and improve their integrity and function. Players may benefit from the provision of higher quantities of protein than are needed by the general population. The RDA for protein is $0.8 \mathrm{~g} / \mathrm{kg} \mathrm{BM} /$ day in Europe, ${ }^{100}$ but higher intakes up to $1.6-2.2 \mathrm{~g} / \mathrm{kg} \mathrm{BM} /$ day appear to enhance training adaptation. ${ }^{101}$ Such levels of protein intake can easily be achieved from a mixed diet provided the energy intake is sufficient to meet the demands of training. ${ }^{102}$ Recent dietary surveys suggest that most professional players report meeting or exceeding the $1.6-2.2 \mathrm{~g} / \mathrm{kg} \mathrm{BM} /$ day protein intake recommended for football. In professional players from the English Premier League, reported daily intakes of protein averaged $2-2.5 \mathrm{~g} / \mathrm{kg}$ $\mathrm{BM} /$ day and were consistent across a 7 -day in-season training period. ${ }^{16}$ This intake (approximately $200 \mathrm{~g} /$ day) was greater than that previously reported $(<150 \mathrm{~g} /$ day $)$ by adult players from the Scottish ${ }^{103}$ and Dutch ${ }^{104}$ leagues and is around twice the RDA in Europe, as previously highlighted. With judicious dietary planning, protein supplements are probably not needed for most players, although they provide a convenient and easily digestible alternative to foods, especially in the post-training period. 
Where protein supplements are consumed at a dose of $0.3-0.4 \mathrm{~g} /$ $\mathrm{kg} \mathrm{BM} / \mathrm{meal}$, whey protein is considered a prudent choice owing to its higher leucine content and digestibility. ${ }^{105}$

Ideally, three to four discrete protein-containing meals should be consumed each day, with at least $\sim 0.4 \mathrm{~g} / \mathrm{kg} \mathrm{BM} / \mathrm{meal}$, which at four meals would provide $\sim 1.6 \mathrm{~g}$ protein $/ \mathrm{kg} \mathrm{BM} /$ day. ${ }^{101}$ This strategy requires a plan to include protein-rich foods at each eating occasion to provide a sufficient dose to stimulate protein remodelling. Protein quality may be important for players as the amino acid leucine, is an important trigger for muscle protein remodelling and $\sim 2.5 \mathrm{~g}$ of leucine per meal would be optimal. ${ }^{105}$ Leucine content is highest in dairy-based proteins ( $2.5 \mathrm{~g}$ leucine $/ 25 \mathrm{~g}$ serve of whey protein), high in meat $(2.5 \mathrm{~g}$ leucine $/ 140 \mathrm{~g}$ of lean beef or boneless chicken breast), eggs (2.5 g leucine/5 standard eggs) and plant-protein isolates like soya ( $2.5 \mathrm{~g}$ leucine $/ 30 \mathrm{~g}$ serve of isolated soya protein). ${ }^{105}$ Plantbased proteins can also be used, but a higher protein intake is required for the same effect on muscle protein synthesis. ${ }^{105}$ As in the general population, football players often exhibit a skewed pattern of daily protein intake (the hierarchical order in which protein is consumed being dinner $>$ lunch $>$ breakfast $>$ snacks), which while potentially meeting their daily protein intake ( $1.6 \mathrm{~g}$ protein $/ \mathrm{kg} \mathrm{BM} /$ day) does not optimally stimulate protein synthesis on each meal occasion, although footballers are reported to consume $\sim 0.3-0.4 \mathrm{~g} / \mathrm{kg} \mathrm{BM}$ at main meals, ${ }^{66}$ in line with current recommendations.

Emerging research on presleep protein consumption suggests that this is an important consideration for football players. Overnight is a natural regenerative phase and yet is also a time when nutrient intake is usually low or absent. Preliminary evidence supports presleep protein ingestion ${ }^{106} 107$ at a dose of $\sim 0.4 \mathrm{~g} /$ $\mathrm{kg} \mathrm{BM}$ within 3 hours of bed in a full meal or perhaps $0.5 \mathrm{~g} / \mathrm{kg}$ $\mathrm{BM}$ if consumed as supplemental protein 1-2 hours before bed to improve training adaptation during periods of high training volume. ${ }^{66}$ Professional players have typically reported an intake of only $0.1 \mathrm{~g} / \mathrm{kg} \mathrm{BM}$ at this time-point, highlighting an opportunity for improved nutritional choices that would potentially improve training adaptation. ${ }^{66}$

During energy restriction, protein requirements are likely increased due to the catabolic milieu created by an energy deficit. $^{108} 109$ Nonetheless, it is possible, even during a severe energy deficit, at least for athletes with high body fat, to lose fat and gain muscle simultaneously. ${ }^{108}$ For this reason, it is prudent to recommend a higher protein intake (perhaps $2.0-2.4 \mathrm{~g} / \mathrm{kg}$ $\mathrm{BM} /$ day) that is dependent on training load and other metabolic stresses, such as weight loss or rehabilitation from injury (see the section 'Expert group statement topic 7' on nutrition for injury rehabilitation). ${ }^{94110}$

\section{Fat requirements for training}

Dietary fat is an important part of a player's training nutrition as an energy source, a vehicle for the intake and absorption of fatsoluble vitamins and a source of essential fatty acids. Adequate intakes of linoleic acid (an omega- 6 fatty acid) and $\alpha$-linolenic acid (an omega-3 fatty acid) typically provide $\sim 10 \%$ of the overall dietary energy intake of sedentary people. ${ }^{111}$ Athletes are often advised to adjust fat intake to allow protein and $\mathrm{CHO}$ requirements to be met within total energy targets and to follow community guidelines regarding the minimal intake of trans fatty acids and caution with the intake of saturated fats. This typically leads to a fat intake of $20 \%-35 \%$ of total dietary energy. While some players may restrict fat intake to reduce total energy intake or because they think it is 'healthy', overrestricting fat intake to
$<15 \%-20 \%$ of energy often requires an unnecessary avoidance of a range of foods with valuable nutrient profiles. At the other end of the spectrum, there is renewed interest in chronic adaptation to a ketogenic low-CHO, high-fat (LCHF) diet to enhance the capacity for fat utilisation during exercise. ${ }^{112}$ Although there are anecdotal reports that some professional football players or teams follow such a diet (or a low-CHO (LC) diet), no observational or intervention studies involving team sports and LCHF diets are available. Furthermore, it has been shown that although trained muscle can use large amounts of fat at relatively high exercise intensities (eg, up to $75 \% \mathrm{VO}_{2} \max$ ) when $\mathrm{CHO}$ availability is limited, this is associated with an increased oxygen cost/ reduced exercise economy which may at least partially explain the impairment of performance at higher exercise intensities. ${ }^{113}$ Due to the lack of evidence, an LCHF diet is not recommended for footballers.

\section{Essential micronutrients for training}

For elite footballers, the demands of both training and match play may also increase the requirements for some micronutrients to support metabolic processes within the body. There are many different classifications of micronutrients, including vitamins, minerals and trace elements essential for growth and development of the body. The most frequent cases of suboptimal status and key recommendations are outlined below.

\section{Vitamin D}

Vitamin D is a controversial topic in sports nutrition. Inadequate serum vitamin $\mathrm{D}$ concentrations have been reported to impair muscle function and recovery ${ }^{114}$ and to compromise immune health, ${ }^{115}$ so it is essential that football players who are deficient are identified and treated accordingly. It is a unique vitamin in that it can be synthesised in the skin via sunlight exposure, with $<20 \%$ of daily needs typically coming from the diet. ${ }^{116}$ The average daily intake across the world is approximately 100-250 IU (1 ug = $40 \mathrm{IU})$, which is less than the current RDA of $400 \mathrm{IU}$ (UK) and $600 \mathrm{IU}$ (North America). The ability to synthesise vitamin D from sunlight is dependent on geography and meteorology, with UVB radiation being insufficient to convert 7-dehydrocholesterol in the skin to vitamin $\mathrm{D}$ at high latitudes, especially in the winter months. Paradoxically, studies demonstrate that, compared with Caucasians, black and Hispanic people are at elevated risk of vitamin D deficiency (with darker skin colour reducing synthesis) but at lower risk of osteoporosis, rapid bone loss and associated fractures. ${ }^{116}$ Given that many footballers reside in countries far from the equator, and that many of them use sunscreen during the summer months, it is not surprising that footballers ${ }^{117}$ occasionally present with vitamin D deficiencies. English Premier League football players showed a seasonal pattern in vitamin D status, with $65 \%$ of players presenting with inadequate serum concentrations of $25(\mathrm{OH}) \mathrm{D}$ (25-hydroxy vitamin $\mathrm{D}$, the best marker of vitamin D status) in the winter months. ${ }^{118}$ Low intakes have also been recorded in female players. ${ }^{119} 120$ The current target serum $25(\mathrm{OH}) \mathrm{D}$ concentration defined by the US Institute of Medicine and European Food Standards Agency is $50 \mathrm{nmol} / \mathrm{L}$, although this may be conservative ${ }^{121}$ and it would be reasonable for athletes to aim for serum 25(OH)D concentrations of at least $75 \mathrm{nmol} / \mathrm{L}$. There is emerging evidence that athletes can have too much supplemental vitamin $\mathrm{D}^{122}$; therefore, if a deficiency is observed, $2000 \mathrm{IU} /$ day of vitamin $\mathrm{D}_{3}$ is suggested with retesting to confirm postsupplementation levels. 


\section{Iron}

Iron is the functional component of haemoglobin and myoglobin as well as being an essential constituent of non-haem sulphur enzymes and haem-containing cytochromes involved in oxidative ATP production. Therefore, iron deficiency, even without anaemia, can have negative implications for aerobic performance. ${ }^{123-125}$ Due to regular blood loss during menstrual bleeding (and possibly due to a diet less rich in meat), postpubertal female players are at the highest risk of iron deficiency. ${ }^{126127}$ While iron deficiency in athletes is common, with a prevalence of about $15 \%-35 \%$ in female athletes and $5 \%-11 \%$ in male athletes, ${ }^{128}$ data on professional football players at various stages of the season are limited. Iron deficiencies may present as lethargy and reduced performance and can be identified through blood screening. A reasonable time frame for assessment of iron status is once per year in male players and twice per year in female players (more frequently when iron deficiency has been detected in recent monitoring).

Anaemia is considered present when blood haemoglobin levels are $<115 \mathrm{~g} / \mathrm{L}$ (females) or $<125 \mathrm{~g} / \mathrm{L}$ (males), although some laboratories may use slightly different cut-off values. Iron deficiency is defined as low serum ferritin $(<35 \mu \mathrm{g} / \mathrm{L}$ ) and normal (ie, not yet affected) blood haemoglobin values. In young athletes, iron deficiency represents the most frequent cause for anaemia; it is typically tested for by determining serum ferritin, the most established marker for the amount of stored iron. ${ }^{129130}$ Anaemia in the presence of low serum ferritin indicates that the anaemia is due to iron deficiency. For anaemia with regular ferritin values, it is necessary to consider other possible causes. In the cases of iron deficiency anaemia, there is a need for iron substitution. When only ferritin is lower than normal, a diet rich in iron, particularly red meat, is recommended to avoid the development of overt anaemia and make sure that other haem-containing proteins/ enzymes can be maintained at a sufficient level. Additionally, a period of iron supplementation may be considered at levels above the RDA after consultation with qualified medical and dietetic practitioners. Parenteral (ie, intravenous) supplementation is usually not indicated. Only in cases of pathologically impaired iron digestion from the gut (such as in coeliac disease) is an intravenous administration justified, also with further consideration of maximum infusion volumes outlined by the most recent antidoping regulations. Determination of transferrin saturation can be an alternative means of assessing iron status when ferritin is not available. ${ }^{130}$ This sometimes occurs when an infection or inflammation is present at the same time because ferritin is an acute-phase protein and typically increases slightly during such episodes.

Low iron status may result from red cell haemolysis, gastrointestinal bleeding, sweating, inflammation, menstruation in female players and inadequate dietary intake. ${ }^{131} 132$ The bioavailability of dietary iron is substantially lower in vegetarian diets than meat-based diets, so the growing interest in veganism is a concern with regard to dietary iron content. The current RDA for iron is $18 \mathrm{mg}$ (in North America) or $14.8 \mathrm{mg}$ (in the UK) for females, and $8 \mathrm{mg}$ (North America) or $8.7 \mathrm{mg}$ (UK) for males. Where possible, iron should be consumed from highly bioavailable sources (haem iron), including meat and seafood. Vitamin $\mathrm{C}$ should be co-ingested with non-haem iron sources to enhance absorption, and foods or fluids that impair iron absorption, such as tea and coffee, should be avoided around meal times. Numerous oral iron preparations are available, and most are equally effective if appropriately taken. Gastrointestinal side effects of supplementation can include constipation, nausea
Table 2 .Food sources of calcium

\begin{tabular}{ll}
\hline Food and serving size & Calcium content $(\mathbf{m g})^{*}$ \\
\hline Whole or skimmed cows' milk $(200 \mathrm{~mL})$ & 240 \\
Calcium-enriched soy milk $(200 \mathrm{~mL})$ & 240 \\
Hard cheese, for example, cheddar $(30 \mathrm{~g})$ & 220 \\
Yoghurt $(120 \mathrm{~g})$ & 200 \\
Sardines, with bones $(1 / 2 \mathrm{tin})$ & 258 \\
Broccoli (2 spears) & 34 \\
Kale (67g) & 100 \\
Orange (1 medium size) & 75 \\
\hline Typical multivitamin/mineral supplement & 200 \\
\hline
\end{tabular}

*Note that the RDA is $700-1000 \mathrm{mg} /$ day.

$\mathrm{RDA}$, recommended dietary allowance.

and black stools. The tolerable upper intake level (UL) is $45 \mathrm{mg} /$ day; high-dose iron supplements of $>45 \mathrm{mg}$ /day elemental iron should not be taken unless iron deficiency is present, as there is a real danger of harmful iron toxicity. For further information on iron considerations, readers are directed to a review by Sim et al. ${ }^{128}$

\section{Calcium}

Calcium is important for the maintenance of bone tissues, skeletal muscle and cardiac contraction and nerve conduction. Serum calcium concentration is tightly regulated by calcitonin and parathyroid hormone regardless of acute calcium intake. The largest store of calcium in the body is in the skeleton and this store is mobilised when dietary intake is inadequate, leading to demineralisation of bone tissue through the action of parathyroid hormone. Dairy products are the main dietary sources of calcium, but it is also found in green leafy vegetables, nuts and soya beans (table 2) The RDA for calcium is $1000 \mathrm{mg} /$ day (North America) or $700 \mathrm{mg} /$ day (UK) for adults and $1300 \mathrm{mg} /$ day (North America) or $1000 \mathrm{mg} /$ day (UK) for adolescents. An athlete's diet should include a higher intake of $1500 \mathrm{mg} /$ day through dietary sources or supplementation if required to optimise bone health in cases of relative energy deficiency in sport (RED-S). ${ }^{133}$ Calcium may be lost through sweat, although modestly; this can hypothetically reduce serum ionised calcium concentration, resulting in an increase in parathyroid hormone production, thus stimulating bone resorption. ${ }^{134}$ Significant dermal calcium losses have been reported following prolonged exercise alongside an increase in parathyroid hormone. ${ }^{135}$ In support of this hypothesis, ingestion of $1350 \mathrm{mg}$ of calcium 90 min prior to exercise has been shown to attenuate deleterious changes in biomarkers of bone resorption. ${ }^{136}$ This suggests that dermal sweat losses, as well as urinary losses, ${ }^{137}$ although small, may be an important consideration. Particular attention should therefore be given to football players training or competing in hot environments, especially if they have low dietary calcium intakes. If supplements are to be used, calcium carbonate and calcium citrate are well absorbed. Finally, recent research has highlighted that magnesium is an emerging consideration with its role in energy production, muscle function, bone heath, immune function and pain modulation. A recent 8 -year study in Olympic athletes highlighted $22 \%$ of athletes were deficient (estimated from erythrocyte magnesium concentration) at one time-point. Furthermore, athletes with a history of Achilles or patella tendon pain had significantly lower magnesium levels than average. ${ }^{138}$ 


\section{Staying healthy throughout the season}

The high physical and psychological demands of participation in elite football may weaken immunity and increase the risk of illness. ${ }^{139} 140$ The most common illnesses in elite footballers are those affecting the respiratory tract $(58 \%)$ and gastrointestinal tract (38\%), with an incidence of 1.5 illness episodes per 1000 player-days. ${ }^{141}$ Several factors are associated with increased risk of illness, including preseason training (higher training load and low energy intake to implement weight loss strategies for some players), winter months, fixture congestion, ${ }^{92}$ psychological stress and depression. ${ }^{139} 142143$ Poor oral health has also been reported in elite players, ${ }^{144}$ with pain, psychosocial impacts and effects on eating and sleeping affecting their ability to train, their MD performance and their recovery. Players should take responsibility for their oral health aided by their existing medical team and a dentist.

\section{Preventing illness in players}

Preventing or at least minimising the risk of illness is a key component in player health management. Illness prevention strategies are important to achieve uninterrupted training and to reduce the risk of illness that can prevent participation or contribute to underperformance in both training and matches. Several nutritional strategies may be effective in helping immunity, ${ }^{145} 146$ although other considerations are just as important in reducing infection risk, including good personal, home and training venue hygiene, managing the training and competition load, ensuring adequate recovery and sleep, psychological stress management and monitoring players to detect early signs and symptoms of illness, overreaching and overtraining. ${ }^{139}$

\section{Nutritional strategies to limit illness risk}

Performance teams can consider adopting nutritional measures to maintain robust immunity in players. ${ }^{145} 146$ For most players, and particularly for those who are illness-prone, these should be implemented throughout the season or at least during the autumn and winter months and during periods of fixture congestion, when infection risk is highest. Adequate levels of essential nutrients are important to support immune health. Inadequate protein-energy intake or deficiencies in certain micronutrients (eg, iron, zinc, magnesium, manganese, selenium, copper, vitamins $\mathrm{A}, \mathrm{C}, \mathrm{D}, \mathrm{E}, \mathrm{B}_{6}, \mathrm{~B}_{12}$ and folic acid) decrease immune defences against invading pathogens and make the individual more susceptible to infection. ${ }^{145} 146$ Low energy availability (EA) is associated with increased risk of illness, and restricting $\mathrm{CHO}$ (eg, 'training low') may increase immunosuppressive stress hormone responses. ${ }^{140}$ Protein intakes of at least $1.2 \mathrm{~g} / \mathrm{kg} \mathrm{BM} /$ day are required for optimal immune function ${ }^{147}$ and there is some evidence, in cases of overreaching, that even higher intakes (up to $3 \mathrm{~g} / \mathrm{kg} \mathrm{BM} /$ day) can reduce the incidence of respiratory infection. ${ }^{148}$ In general, a broad-range multivitamin/mineral supplement is the best choice to support food intake in situations where food choices and quality may be limited. Several studies in athletes and the general population have provided evidence of the importance of vitamin D status in optimising immune defence against the common cold. ${ }^{115}{ }^{116}$ Hence, players who are deficient or insufficient in vitamin $\mathrm{D}$ are likely to benefit from vitamin $\mathrm{D}_{3}$ supplementation (2000 IU/day to correct a deficiency or to avoid the possibility of a deficiency during the winter months). Taking $75 \mathrm{mg} /$ day of zinc supplements (lozenges) when symptoms of a cold begin is reported to reduce the duration of symptoms. ${ }^{140} 149$

High intakes of fresh fruit and vegetables are associated with reduced infection risk in highly physically active people, ${ }^{145} 150$ therefore footballers should follow the standard recommendation of at least five portions of fruit and vegetables per day on at least 5 days per week. Several studies in athletes indicate that daily consumption of polyphenol supplements ${ }^{151} 152$ or beverages (eg, non-alcoholic beer, green tea) ${ }^{152153}$ is also associated with reduced respiratory infection risk in athletes. Footballers should limit alcohol intake to no more than 2 units per day and avoid binge drinking, which is known to negatively impact the functioning of immune cells. ${ }^{84}$

Some well-controlled studies in athletes have indicated that daily probiotic ingestion results in fewer days of respiratory illness and lower severity of illness symptoms, ${ }^{145}{ }^{154}$ with general support for a reduced incidence of respiratory illness being provided by a recent meta-analysis of data from 12 studies involving both athletic and non-athletic populations. ${ }^{155}$ These benefits have been limited to protocols involving Lactobacillus and Bifidobacterium species, with daily doses of $\sim 10^{10}$ live bacteria. A smaller number of studies indicate that probiotics may also reduce the severity and/or duration of gastrointestinal illness in athletes. ${ }^{154}$ Currently, there is insufficient evidence to justify the use of any other supplements to boost immunity and/ or reduce infection incidence.

Finally, serious gastrointestinal illness caused by bacterial contamination may occur in relation to the storage and preparation of food consumed in training ground restaurants or venues used for postmatch buffets (eg, the changing room or team bus). Minimising the risk of such problems requires attention to food hygiene, with a focus on cross-contamination, cleaning, chilling and cooking. Resources that address these ' $4 \mathrm{Cs}$ ', including hygiene training documents and videos, can be found on the UK Food Standards Agency website (www.food.gov.uk/businessindustry/food-hygiene).

\section{EXPERT GROUP TOPIC 3: BODY COMPOSITION}

Nutrient intakes can have a profound impact of a player's body composition which in turn may impact their performance. There are different time points throughout the season where players may need to manipulate their intake to elicit changes in fat mass (FM) or skeletal muscle mass (fat free soft tissue mass (FFSTM)). ${ }^{156}$ This may occur during preseason or during injury where nutrient intake may need to be altered to the needs of physical output. ${ }^{157}$ This relationship is very important to the athlete's health and performance as it is often not reflected in BM measurement alone.

The sports nutritionist and performance team are required to work closely to plan out how the interaction between diet and training will change body composition. These interventions should be justified, well planned out and executed. ${ }^{158}$ Increased FFSTM may be a desired training adaptation with benefits of enhanced strength and power. Moreover, the preservation of FFSTM during injury and immobilisation is crucial. ${ }^{33} 159$ In contrast, excess body fat will negatively affect a player's powerto-weight ratio, acceleration capacity and overall energy expenditure. ${ }^{160}$ However, players may also choose to manipulate body composition (FFSTM or FM levels) to achieve a desired appearance, and the desire for a lean or muscular physique may conflict with the player's performance goals. Each player's body composition goals should be agreed between the player and the performance team.

\section{Assessing body composition}

Methods of assessing body composition in football must be valid, reliable and practically feasible to monitor meaningful change, 
with four or five compartment (4C or $5 \mathrm{C}$ ) methods remaining the criterion method of assessment, known as gold standard. Adherence to standardisation in any assessment protocol will assist minimising technical and biological error and allow recognition of the smallest meaningful changes and therefore improve longitudinal tracking of body composition. ${ }^{161}{ }^{162}$ Field methods such as anthropometry (skinfolds), bioelectrical impedance analysis and ultrasound are all commonly used with degrees of accuracy and precision in athletic populations. ${ }^{163-167}$ Many of the current laboratory methods including underwater weighing, air displacement plethysmography, isotope dilution methods, MRI, three-dimensional photonic scanning and dual X-ray absorptiometry (DXA) have precision errors between $1 \%$ and $4.5 \%,{ }^{164}$ but are not often easily accessible, expensive and may require high levels of expertise to process and interpret results.

With advancements in technology and reductions in costs, there is a recent shift toward the use of DXA scanning to assess body composition including bone mineral density in elite athletes. Indeed, there have been many studies that have described the body composition of a wide array of different athletes in numerous sports that have used the field method of DXA. There have now been several validation studies, mostly in healthy humans, showing that DXA has greater levels of accuracy than alternate methods such as skinfold-derived body fat or bioelectrical impedance analysis measures. ${ }^{168} 169$ In fact, several validation studies with various manufacturers of DXA have shown a similar level of accuracy as the $4 \mathrm{C}$ model. ${ }^{170} 171$ Indeed, recent research has demonstrated that the DXA-derived FM percentage was strongly associated with a gold standard 5C model $(24.4 \% \pm 12.0 \%$ vs $24.9 \% \pm 11.1 \%, r=0.983$, $\mathrm{p}<0.001) .{ }^{172}$ Due to several manufacturers and software, many different DXA units, while not interchangeable, showed exceptionally good precision and accuracy for FFSTM, bone mineral content and FM and may be more appropriate when assessing change in leaner athletic populations in comparison to other practical methods, namely anthropometry and bioelectrical impedance analysis. ${ }^{173}$

Ensuring standardisation in positioning, food and hydration status will reduce errors associated with the use of DXA. ${ }^{161} 162174$ Practitioners must recognise that radiation exposure, although generally small, will limit the frequency of measurements, so the timing of assessments should be carefully planned. Anthropometry provides an acceptable, cost-effective, practical, assessment of body composition, when conducted by someone with appropriate kinathropometric training (eg, International Society for the Advancement of Kinanthropometry). The use of absolute skinfold measurements is recommended to assess changes in body composition rather than calculating percentage body fat using equations. ${ }^{175}$

\section{What is the optimum body composition for an elite football player?}

The optimum physique, in terms of FFSTM and FM levels, varies according to an individual player's physiology, and their field position and playing style. Indeed, there is no single value for either BM or FM content against which targets or judgements should be made. Mean FM levels in elite male players measured by DXA typically range from $\sim 8 \%$ to $13 \%,{ }^{93} 176$ although lower ${ }^{158}$ and higher ${ }^{177}$ values have also been recorded. Goalkeepers are typically taller and heavier with greater FM than outfield players. ${ }^{158}$ Elite senior male players have, on average, higher FFSTM than players in under (U)21 and U18 teams, although differences in FM may not be significant. ${ }^{93}$ Data on elite female players are scarce, but mean FM levels of approximately 16\% have been observed in US collegiate division 1 players. Most elite clubs regularly monitor players, and this area of research will continue to evolve in terms of position-specific and seasonal trends. To date, it appears that seasonal changes typically include lower FM and greater FFSTM mid-season and at the end of the season. ${ }^{176}$

Notwithstanding these observations, both male and female players may perform well with FM levels outside the normally accepted range: it is not known if a change in physique would result in better performance. Performance metrics, such as training or match data (eg, GPS) or functional tests (eg, countermovement jumps), alongside body composition may help to provide objective feedback as to what is appropriate for each player.

\section{Relative energy deficiency in sport}

In an attempt to conform to various self-imposed expectations or demands from others, many female athletes restrict energy intake and develop the clinical syndrome originally known as the female athlete triad ${ }^{178}$ and later introduced as RED-S ${ }^{179}$ applicable in both male and female athletes with or without disordered eating (DE) or eating disorders (ED). Although football is not considered one of the high-risk sports for RED-S ${ }^{179}$ or $\mathrm{DE},{ }^{180}$ it should be noted that only a few studies have evaluated markers of low EA ${ }^{181}$ and conditions associated with RED-S and/ or DE in football players. ${ }^{132}$

Reed et $_{\mathrm{al}} \mathrm{l}^{181}$ assessed EA based on the match between reported energy intakes and training expenditure in the NCAA women's division I; they found that $26 \%, 33 \%$ and $12 \%$ of players met the criteria for low EA preseason, mid-season and postseason, respectively. It is known, however, that such assessments are fraught with errors of reliability and validity. ${ }^{182}$ Meanwhile, Prather $e t a l^{183}$ investigated 220 female football players representing a youth club, an NCAA division I university team, and a women's professional team to identify components and outputs of low EA; they found that $8 \%$ were at risk for ED, while $19 \%$ had menstrual dysfunction and $9 \%$ reported stress fractures. In a study of 17 female Norwegian junior and senior national team football players, $24 \%$ had DE, $9 \%$ had menstrual dysfunction and $13 \%$ reported a history of stress fractures. ${ }^{132}$ The contribution of low EA to bone health and injury rates is one of the key reasons for concern about energy mismatches, and it has been identified as a problem in males as well as females. ${ }^{181}$ Indeed, a recent study of male and female endurance runners by Heikura et $a l^{184}$ found a 4.5 -fold increase in bone injury rates with low EA in $37 \%$ of females (with amenorrhoea) and $40 \%$ of males (with low serum testosterone). Factors which may contribute to low EA include changes in BM and composition, and changes to training volume/intensity without associated changes to fuelling. ${ }^{179}$

The management of body composition in football requires knowledge and skills in how to approach an athlete with unrealistic expectations, methods or goals regarding lower FM, how to present/discuss the results of body composition assessments and when to raise the alarm and engage other support staff, to prevent severe energy restriction or EDs. ${ }^{175}{ }^{180}$ It is also recommended that team protocols are standardised to ensure that monitoring is undertaken precisely, accurately and longitudinally, that body composition data are integrated with other test parameters, and that team support staff are aware of the health risks associated with RED-S and DE. 


\section{EXPERT GROUP TOPIC 4: STRESSFUL ENVIRONMENTS AND TRAVEL}

When matches are played in stressful environments, the cardiovascular, thermoregulatory, metabolic and perceptual strain is exacerbated. ${ }^{185}{ }^{186}$ Heat exposure is a widely recognised risk, with increased sweat loss and dehydration presenting a threat to performance and health. ${ }^{187}$ Conversely, exposure to cold and high-altitude environments stimulates diuresis, increases respiratory water loss and reduces thirst, again predisposing athletes to dehydration. ${ }^{185}$ Furthermore, international fixtures, major tournaments and preseason training camps can require extensive long-distance air travel, with exposure to dry cabin air and altered access to fluid and nutritional intakes potentially resulting in mild-to-moderate dehydration. ${ }^{188}$ Congested competitive schedules seldom permit prior exposure to these environments, and although exposure to heat, altitude or travel may be brief, rarely is physiological or perceptual acclimatisation available to attenuate the strain. A range of thermoregulatory, sleep and travel interventions exist to assist in these environments; however, with the exception of heat, there is limited evidence for recommended nutritional strategies to further support players exposed to match demands in stressful environments. In this section, we focus on playing in hot environments and make some reference to the limited information pertaining to nutritional interventions in other stressful environments, in the hope of stimulating future research in these areas.

\section{Hot environments}

Important matches are often played in hot conditions, such as the UEFA Champions League final (played in May each year) and the UEFA European Football Championship or FIFA World Cup finals (played in June and July every 4 years). Football matches in the heat result in decreased total and high-intensity distance covered, partly compensated for by altered technical engagement, for example, increased successful passes and crosses. ${ }^{186}$ Furthermore, increased deep organ and muscle temperatures, alongside similar cardiovascular responses for reduced match work rates, highlight the increased thermal strain of playing in the heat. ${ }^{186}$

In hot environments, dehydration potentiates hyperthermia, increases cardiovascular strain and elevates perceived exertion. Specifically, a body weight loss of 3\%-4\% induced by dehydration may decrease muscular strength by $2 \%$, power by $3 \%$ and high-intensity exercise endurance by $10 \% .{ }^{189}$ Field measurements of sweat losses during football training show increasing sweat rates as ambient temperature increases. ${ }^{54}$ Laboratory studies indicate that ambient temperature, ${ }^{190}$ humidity ${ }^{191}$ wind speed ${ }^{192}$ and solar load ${ }^{192} 193$ all influence endurance performance. While UEFA competitions implement designated 3 min cooling breaks during each half when temperatures are $>32^{\circ} \mathrm{C}$ dry bulb and $>27^{\circ} \mathrm{C}$ wet bulb globe temperature, further interventions such as precooling may assist player performance and health. The risk of players experiencing significant hypohydration is exacerbated when training or playing matches in the heat. Accordingly, the primary nutritional needs of players in a hot environment are to replace fluid and sodium losses. It is not necessary to drink to fully compensate sweat losses but, as a guide, BM loss should be restricted to less than about $2 \%-3 \%$ of the starting mass. ${ }^{194}$ Important additions to rehydration beverages therefore include $\mathrm{CHO}$ and electrolytes (particularly sodium) to optimise football performance. $^{4546178}$

When rehydration is the priority, ingesting a $2 \%-6 \% \mathrm{CHO}$ beverage may be of greater benefit to the player than more concentrated solutions, which can slow the delivery of fluid to the body. ${ }^{195}$ It is also recommended that $\mathrm{CHO}$ intake after the warm-up and at half-time is reduced to $\sim 20-50 \mathrm{~g}$, when fluid intake is prioritised over substrate delivery. Furthermore, providing chilled beverages will promote voluntary fluid intake $^{196}$ and can limit the rise in core temperature that would otherwise occur. ${ }^{197}$ In particular, CHO-infused ice-slushies offer an appealing strategy for cooling, rehydrating and nutritional replenishment.

The few players who have both a high sweat rate and a high sweat sodium concentration (which can be determined using validated sweat composition testing) should receive individualised guidance and monitoring of salt and fluid intake. However, the whole-body balances of water, sodium and potassium are complex and determining the dietary intake required to replace sweat and urine losses requires considerable technical expertise and laboratory instruments. ${ }^{198}$ The ideal solution involves accurate diet records, urinalysis and whole-body sweat analyses. ${ }^{182}$ Other methods (eg, estimation, normal clinical values, extrapolation of local sweat collections) fail to characterise an athlete's fluid-electrolyte turnover accurately. When the support of a sports nutritionist, exercise physiologist or sports medicine physician is not possible, we recommend two actions: first, consume ample fluids and foods with high sodium, potassium and water contents. ${ }^{199}$ Second, self-assess hydration status each morning by recording body weight, assessing thirst and observing urine colour. ${ }^{200}$

\section{High altitudes and cold environments}

Matches played at altitude are the least common of the stressful environments for practitioners to plan for. The most notable include matches in La Paz, Bolivia $(\sim 3600 \mathrm{~m})$. Altitude $(>1500 \mathrm{~m})$ results in decreased running performance for unacclimatised players. ${ }^{185201}$ At elevations $>1500 \mathrm{~m}$, appetite decreases and food preferences change, ${ }^{202}$ so that both the absolute and voluntary consumption of $\mathrm{CHO}$ increases at the expense of fat and protein. Also, endurance exercise performance is adversely affected if diet is manipulated to decrease $\mathrm{CHO}$ intake. Easily consumed liquid or solid $\mathrm{CHO}$ foods can help to maintain performance and macronutrient balance. When residing at altitude for more than a few days, for example, during altitude training camps, maintenance of body weight (ie, ensuring adequate daily energy and water intake) is a priority. ${ }^{203}$ Above an altitude of $3000 \mathrm{~m}$, the increased production of red blood cells may require an adequate dietary iron intake $(100-300 \mathrm{mg}$ of elemental iron per day), ${ }^{204}$ but this should be guided by the team doctor based on an individual player's iron status; particularly for extended camps if predeparture iron is low. ${ }^{205}$ Given the lack of evidence on nutrition-based interventions for competition at altitude, further research is required.

While some matches may be played in extreme heat, others may be played in cold conditions, including some UEFA Champions League matches or other leagues around the world. Players can cope with cold environments by wearing appropriate clothing. Provided the weather is not extreme and the work rate is maintained at a high level, cold should not be a problem if appropriate clothing is worn. UEFA regulations on playing in the cold specify that when the temperature is $-15^{\circ} \mathrm{C}$ or colder, the match is postponed unless both teams agree to play. $\mathrm{CHO}$ requirements are increased in cold environments, while the effects of dehydration may be less detrimental to performance. ${ }^{2}$ However, further research is needed to determine the effects of 
playing in the cold and how nutritional strategies might be able to help.

\section{Flying across time zones}

The speed and power of professional footballers are reduced in the aftermath of long-haul travel ( $>15$ hours) across multiple time zones ( $>4-5)$, although it is reportedly possible to maintain prolonged intermittent-sprint performance. ${ }^{206}$ It is likely that reduced performance exists with travel distances of $>10$ hours and 2-3 time zones. The disrupted sleep patterns resulting from desynchronisation of endogenous circadian rhythms and external day-night cues (ie, jet lag), concurrent with reduced mood and motivation (ie, travel fatigue), are the likely causes of reduced player performance for up to 72 hours following travel. The severity of this disorder is proportional to the number of time zones crossed and the cumulative sleep loss, thus primary interventions that target improved sleeping behaviour, limit perceived fatigue and improve motivation are important. ${ }^{207}$

Light is the most powerful external regulator of circadian rhythms. Dietary manipulations such as moderating food amount, type and intake patterns have been proposed, ${ }^{188}$ but the evidence does not support any method unequivocally. ${ }^{208}$ Oral melatonin, ${ }^{209}$ slow-release caffeine ${ }^{210}$ or a combination of the two may reduce the negative consequences of jet lag. ${ }^{210}$ There are important considerations around the sourcing and side effects of melatonin and readers are directed to a recent review $^{211}$ for further considerations for travel. All pharmacological sleep interventions should be overseen by a medical doctor, although sleep hygiene (as part of wider travel hygiene) should always be considered first.

\section{EXPERT GROUP TOPIC 5: GLOBALISATION-CULTURAL DIVERSITY AND DIETARY CONSIDERATIONS}

The elite football community has become much more mobile in recent years. This progression has been particularly evident in Europe since the 1995 Bosman ruling, with player migration within the five major European leagues (England, France, Germany, Italy and Spain) increasing from 19\% in 1995/96 to $47 \%$ in 2015/16. Differences in migration are seen across continents: North American Major League Soccer (49\%) and Europe (48\%) have the highest proportion of foreign players (the English Premier League having the highest at 66\%), with lower proportions in Asia (18\%) and Latin America (14\%). ${ }^{212}$ In addition to the evolving diversity of elite teams, there are multiple international club and national team competitions, preseason camps, friendly games and commercial obligations that mean travel to foreign countries is now a common occurrence for elite teams and their players. As a consequence of this increasing globalisation, various related challenges are more apparent for performance and nutritional team staff.

\section{Religious beliefs and implications for dietary practices}

Practitioners should be aware of the cultural considerations for all players. Collaboration with the club chefs is important to ensure all foods provided on training and MDs are culturally acceptable. With approximately $23 \%$ of the world's population being Muslim and $>50$ countries considered Muslim majority nations, ${ }^{213}$ Ramadan is an important consideration for players and a particular challenge for many elite football teams. During the holy month of Ramadan, Muslims fast from sunrise until sunset. Many Muslim players will continue to train and compete during Ramadan, although each must decide how they approach the situation. The available evidence indicates that elite players can maintain most parameters of physical performance over Ramadan, although sleep and nutrition should be optimised to reduce the likelihood of any cumulative fatigue. ${ }^{214}$ For a comprehensive overview on Ramadan in football, readers are directed to Maughan et $a l^{215}$ for further information.

Where possible, training should be scheduled to allow for the most appropriate nutrition support: when training is scheduled after sunset, players can benefit from food and fluid consumption before, during and after training. ${ }^{216}$ Players should make the most of the important meals: Suhour (the predawn meal) should be eaten as close as possible to sunrise and should be high in $\mathrm{CHO}$, as well being used to contribute to daily protein and fluid targets; Iftar (the first meal after sunset) is important to support recovery and may be adapted to meet the overall nutritional needs for the day. ${ }^{216}$ Players should still fuel according to the demands of the training or MD (maintaining the overall intakes outlined in the sections 'Expert group topics 1 and 2' on match and training day nutrition, respectively). Making use of fluids and sports foods may reduce gastrointestinal discomfort. Sufficient fluid and electrolyte intake should be achieved in small amounts spread over the waking hours after sunset, to fully replace sweat losses. ${ }^{216}$

Players should be individually monitored with training loads prescribed accordingly, to reduce the risk of illness and injury, and limit unnecessary dehydration. ${ }^{216}$ Adherents to other faiths and their practices should also be considered, for example, Tisha B'Av, the annual Jewish day of fasting, which coincided with the London 2012 Olympic Games. ${ }^{216}$

\section{Food allergies and intolerances}

A food allergy is defined as an adverse immune-mediated response, which occurs reproducibly on exposure to a given food and is absent when the food is avoided. ${ }^{217}$ Reactions can range in severity from minor abdominal discomfort through to anaphylaxis, with reactions generally developing within minutes of exposure. The most common food allergies include fish, shellfish, peanuts and tree nuts, with some geographical variance. ${ }^{218}$ Food allergy is determined by means of a thorough medical and nutrition history to guide validated diagnostic methods, such as a skin prick measurement of food-specific IgE levels or doubleblind, placebo-controlled food challenges. ${ }^{218} 219$

Food intolerances are reactions which are not immunemediated (eg, lactose or gluten intolerance). The symptoms are less clear, with frequently unspecific symptoms occurring hours to days after exposure, possibly including abdominal bloating or pain, loose stools, fatigue or headache. ${ }^{219}$ At this time, aside from lactose intolerance, there are no validated diagnostic methods for establishing food intolerance. ${ }^{218}$ Coeliac disease is another common condition (autoimmune disease) for which validated medical testing exists. It is important that validated diagnostic testing is conducted, under the guidance of a medical doctor, before undertaking an exclusion diet in response to allergy or intolerance-related symptoms.

\section{Special diets}

There is increasing interest in a more diverse range of diets for football players (and athletes in general) with some consuming and even advocating specific diets such as gluten-free, vegetarian and vegan for performance reasons. The reality is that, despite an increase in the number of players adopting these emerging diets, there has been no scientific research into their effect on football performance. However, it is important to discuss the issue and provide our expert opinion at this time. 
Gluten-free diets (GFDs) have gained popularity among athletes, with $41 \%$ of athletes without coeliac disease reported to consume a GFD at least half of the time. ${ }^{220}$ Following a GFD is essential when managing clinical conditions such as coeliac disease (a serious autoimmune disease of the small intestine triggered by gluten that affects about $1 \%$ of adults) or wheat allergy; many others may follow GFDs due to perceived health or performance benefits, although no differences in gastrointestinal symptoms, systemic inflammation or exercise performance in athletes without coeliac disease have been shown when following a GFD. ${ }^{221}$ Rather than avoiding gluten itself, a low fermentable oligosaccharides, disaccharides, monosaccharides and polyols (short-chain CHOs) diet has been associated with improvements in gastrointestinal symptoms for individuals with non-coeliac gluten sensitivity. ${ }^{218} 222$

There are many different types of vegetarian diet. Vegetarian diets exclude meat, fish and poultry, whereas stricter vegan diets exclude all animal products including dairy, eggs and honey. Other varieties include lacto-vegetarian (permits dairy but not eggs), ovo-vegetarian (permits eggs but not dairy) and flexitarian (includes meat, poultry, fish, eggs or dairy but only occasionally or in small quantities). The recent popularity of vegetarian diets appears to reflect current public trends, although considerable variability exists in different countries. ${ }^{223}$ Approximately $22 \%$ of the world's population is thought to be vegetarian, ${ }^{224}$ although the only study in elite athletes found the prevalence to be $8 \%$. $^{225}$ Although a vegetarian diet has been associated with a reduced risk of chronic diseases in non-athletic populations, ${ }^{226}$ its effect on athletic performance has not been established. ${ }^{218} 227$ A wellbalanced vegetarian diet can provide a full range of macronutrients and micronutrients but, depending on the type of vegetarian diet, may result in lower calcium, iodine, iron, zinc, vitamin $B_{12}$, omega-3 fatty acid and creatine intakes, although protein needs are commonly met in athletes meeting overall energy requirements and eating a variety of protein-rich foods. ${ }^{226}$

Evidence suggests there are health benefits associated with vegetarian diets, but at present there is little evidence that vegetarian diets are superior to omnivorous diets for improving athletic performance. Finally, and as previously detailed in the section 'Expert group topic 2' on training day nutrition, there is little evidence to support a ketogenic, LCHF diet for player performance.

Further work is required to understand the interplay between sports nutrition and sustainability and how principles can be incorporated within best practice nutrition recommendations. Now more than ever, players may also modify dietary habits for their own perceived health, performance or ethical reasons. The literature about this is scarce within athletic populations; readers are directed to a review by Lis $e{ }^{2} l^{218}$ for further information.

\section{Personalised nutrition}

A player's nutrition should be periodised and personalised to meet their training and match demands and individual objectives (eg, reduced body fat or increased muscle mass) but, as highlighted in this section, cultural, religious, ethical, medical and even just individual food preferences will affect a player's food choices.

Due to the risks to health and/or performance associated with many forms of dietary restriction, any major dietary change should be evaluated and monitored under the guidance of the team's sports nutritionist and medical doctor.

Where biomarker testing (ie, blood, urine, saliva) is required to inform any intervention (eg, a blood test for iron or vitamin
D status), it is crucial that this is overseen by the medical and performance support team with input from the sports nutritionist where appropriate. In the face of increasing unvalidated technology available to players and staff, any testing must be both valid and reliable, and used to answer a specific question about an individual player. There is currently a lack of evidence for genetic testing and nutrition prescription.

\section{Food contamination}

The findings of food contamination with the prohibited anabolic agent clenbuterol both in China ${ }^{228}$ and in Mexico, where at the FIFA U-17 World Cup in 2011, a total of 109 out of 208 urine samples yielded clenbuterol findings, although at very low levels, ${ }^{229}$ are a cause for concern. Player vacations and travel for competitions may lead to exposure. Teams should consult their national association or WADA for the latest advice. Player education is crucial, and sports nutritionists may devise meatfree menus or advise eating at recommended outlets to minimise risk. Such precautionary measures can reduce, but not eliminate, the risk of inadvertent exposure to clenbuterol in at-risk countries, for example, Mexico, China and Guatemala, 230 so it is important to inform the relevant antidoping organisations (WADA, National Anti-Doping Organizations, antidoping commissions of national associations) about the whereabouts of individuals and teams.

\section{EXPERT GROUP TOPIC 6: DIETARY SUPPLEMENTS Definition and categorisation of supplements}

Dietary supplements come in many shapes and forms, and any definition or classification system must recognise this diversity. ${ }^{231}$ There is no single definition of a 'supplement' that is completely satisfactory and independent of context. In a recent IOC consensus statement, ${ }^{232}$ the following definition of 'dietary supplement' was proposed:

A food, food component, nutrient, or non-food compound that is purposefully ingested in addition to the habitually-consumed diet with the aim of achieving a specific health and/or performance benefit.

Athletes/players give many reasons for using supplements, and these are often shaped by the promotional materials targeted at them by manufacturers. Claims such as 'build muscle', 'burn fat', 'increase energy' and 'stay healthy' are emotive and highly valued by athletes. It is important to remember, however, that the supplements industry is driven by financial motives and responds to consumer demand and acceptance. The evidence to support these claims is often lacking and may also be at risk of both natural and industry-driven publication bias. In general, the scientific literature favours studies reporting positive findings as they are considered more 'newsworthy', but some of the authors of this statement have also found that studies showing 'positive' effects are promoted while those finding no (or negative) effects may be blocked by sponsors of the research.

\section{Prevalence of supplement use within elite football}

Supplement use is widespread in sport and there is some evidence that its prevalence varies according to the sport, as well as the training and performance level, age, sex and culture of the individuals concerned. ${ }^{231}$ In elite football, only two studies have provided data on the prevalence of supplement use. ${ }^{233} 234$ Aljaloud and Ibrahim $^{233}$ reported that $93 \%$ of 108 players from three different Saudi professional teams regularly used supplements. The most-used supplements were sports foods $(87 \%$ of 
players consumed sports drinks) and vitamins (81\% consumed vitamin C). Studies conducted on national team players during the 2002 and 2006 FIFA World Cups also indicated widespread use of supplements. ${ }^{234}$ Each team physician was asked to document nutritional supplements taken in the 72 hours prior to each match during both tournaments, making the objective validity of these data questionable. Approximately $43 \%$ of players in the 2002 and 2006 tournaments were reported to have used supplements. Sports foods and drinks were not considered supplements in this study, resulting in a lower prevalence than in other studies.

\section{Supplements that may be useful}

The football player's nutritional programme should be centred around a 'food first' approach, with supplements used only to meet specific health and/or performance objectives. The dose and duration of supplementation should be recorded, and responses, including both positive and adverse effects, should be monitored by the team's sports nutritionist in collaboration with other key stakeholders, including the team's medical doctor. Regular review is essential.

Recognising that any system of supplement classification must take into account the needs of many diverse groups, including consumers, manufacturers and legislators, categorisation by target function or action is recommended. While accepting that there is no sound evidence of efficacy in many cases, the classes of supplements listed in table 3 might nevertheless be recognised. Products with very different characteristics might be found within the same category, and some supplements might be found in more than one category. The recommendations here are closely aligned with those of the IOC consensus. ${ }^{232}$

\section{Micronutrients}

Where a player is identified as suffering from a specific micronutrient deficiency, a dietary solution should be sought, although a prompt and effective solution may not always be possible. Micronutrients often requiring supplementation in athletes include vitamin D, iron and calcium. ${ }^{232}$ Supplements used for this purpose should be sourced from a reputable supplier and used only at the therapeutic dose and for the shortest possible time required to restore adequate nutrient status. Players with restricted eating patterns, whether for religious, cultural or ethical reasons, or due to restricted energy intake during periods of weight reduction, may benefit from the use of a broad spectrum, low-dose multivitamin and mineral preparation, but again this should be assessed on an individual basis. These supplements present no major risk for health, except with chronic supplementation and/or high doses. Routine iron supplementation can do more harm than good, and the risk of iron toxicity is very real. ${ }^{235}$ It should also be recognised that athletes who self-prescribe supplements to provide essential nutrients are often those least likely to require them. ${ }^{236}$ Players are therefore advised not to purchase their own supplements but to use only those provided/ recommended by the sports nutritionist, or at least agreed on by the team doctor.

\section{Sports foods}

Footballers should have clear nutritional guidelines to follow on training and MDs. Due to the usual organisation of training sessions in a day (concurrent 'on pitch' sessions followed by resistance work) with limited breaks in training and match play, it is not always possible for players to consume foods in the form of meals. In this situation, sports foods (eg, CHO-electrolyte drinks, gels and recovery shakes) can provide a convenient alternative to meet nutrient targets. Table 3 lists sports foods with supporting scientific evidence that may be considered in the circumstances where 'food-first' is not feasible.

\section{Performance}

Although some dietary supplements may be effective in improving performance in some specific exercise models or sports, very few have undergone football-specific tests and some studies of match play simulations have involved participants with only recreational level experience or an absence of any football experience. The evidence that professional footballers would benefit from these supplements is very limited. Furthermore, based on general methodological considerations it is likely that there are fewer benefits than in other sporting contexts. Since many commonly used supplements will display a large interindividual variability in terms of response, they should be trialled and monitored in training before being used in competition. The evidence for some performance supplements (eg, caffeine, creatine) is stronger than for others ( $\beta$-alanine, nitrate). Sodium bicarbonate was removed from this category by the expert group due to its lack of use within elite football. Negative effects must also be considered, as highlighted in the 'concerns and use' column in table 3. Performance supplements not listed here can be considered to have insufficient evidence to support use.

\section{Supplements and adverse analytical findings}

The risk of a positive doping test resulting from the use of dietary supplements has been recognised for two decades. Both independent analyses carried out by various laboratories and analytical checks carried out by the US Food and Drug Administration have identified contamination of supplements with pharmaceutical agents that are not listed on the label. Geyer et $a l^{237}$ analysed 634 nutritional supplements from 215 different suppliers in 13 countries with $\sim 15 \%$ containing prohormones not declared on the label. In 2007 , it was reported that $\sim 25 \%$ of 58 supplements purchased through US-based outlets were contaminated with steroids. ${ }^{238}$ In a more recent survey, Matthews ${ }^{239}$ concluded that 'poor manufacturing processes and intentional contamination with many banned substances continue to occur in dietary supplements'. Historically, anabolic steroids have been the pharmaceuticals most commonly found in muscle building supplements, while stimulants and anorectic agents are more commonly found in tonics and weight loss supplements, respectively. However, new supplements have appeared on the sport supplements market in recent years, containing a larger variety of different prohibited doping substances. ${ }^{240-243}$ Banned stimulants have been found in so-called training or pre-workout boosters, while muscle building products have been shown to contain prohibited selective androgen receptor modulators, aromatase inhibitors, $\beta_{2}$-agonists, new anabolic steroids and growth hormone releasing peptides. Products containing prohibited diuretics, stimulants and $\beta_{2}$-agonists are frequently advertised as weight loss or fat burner supplements. Also, erythropoiesis-stimulating agents, that is, endurance performance enhancers, were found to contain prohibited inorganic cobalt and nickel. ${ }^{240-243}$ This may be interpreted as supporting the idea that contamination is not accidental, but rather the result of deliberate adulteration of otherwise ineffective products. Inadvertent doping with stimulants and anabolic steroids may also result from the consumption of traditional Asian medicines. ${ }^{241} 244$ The principle of strict liability means that ignorance of the presence of a prohibited substance in a product is not an acceptable excuse and sanctions will still be applied. ${ }^{230}$ 
Consensus statement

Table 3 Dietary supplements, sports foods and beverages that are potentially useful for footballers (adapted from Maughan et al ${ }^{232}$ )

\begin{tabular}{|c|c|c|c|c|}
\hline Type of supplement and examples & Use & Concerns & Main mechanisms & Protocol \\
\hline \multicolumn{5}{|l|}{ Micronutrients } \\
\hline $\begin{array}{l}\text { Vitamin D } \\
\text { Iron } \\
\text { Calcium }\end{array}$ & $\begin{array}{l}\text { Prevent or treat deficiency } \\
\text { to help maintain health and } \\
\text { performance. }\end{array}$ & $\begin{array}{l}\text { Inappropriate use or when } \\
\text { taken with lack of monitoring } \\
\text { or supervision can lead to } \\
\text { health problems. }\end{array}$ & See section on micronutrients. & $\begin{array}{l}\text { According to Doctor's } \\
\text { prescription. }\end{array}$ \\
\hline
\end{tabular}

Sports foods

Carbohydrate (CHO)-electrolyte drinks Supply convenient

CHO gels

Sports bars and confectionery

Recovery shakes

Protein drinks

Protein-enhanced food

Liquid meal supplements

\section{Performance}

Caffeine macronutrients to support

energy or recovery needs for

training and match play.
Greater cost than whole foods. Macronutrient and/or fluid supply. Inappropriate use or amounts

when taken with lack of

monitoring or supervision.
See sections on match day (topic 1) and training (topic 2).
Reduces perception of fatigue, enhances endurance, repeated sprint performance, ${ }^{301} 302$ skill and fine motor control ${ }^{303} 304$ and improves cognitive function. ${ }^{304}$
Highly individual response (both positive and negative). Side effects with high doses

include anxiety, nausea, insomnia, tremors and reduced sleep quality. More serious side effects include tachycardia and arrhythmias.
Central nervous stimulant.

Adenosine receptor antagonist.

3-6 mg/kg BM, in the form of anhydrous caffeine (ie, pill or powder form), consumed $\sim 60$ min prior to exercise or lower caffeine doses $(<3 \mathrm{mg} /$ $\mathrm{kg} \mathrm{BM}, \sim 200 \mathrm{mg}$ ), provided both before and at half-time consumed with a $\mathrm{CHO}$ source. Sports foods (or coffee) provide multiple options for delivery. Dose of caffeine should first be evaluated using lower caffeine doses to assess response, especially if used regularly in training and match play. Note: caffeine is currently on WADA's monitoring programme so the WADA list should be checked prior to use in case of a change in status.

\begin{tabular}{|c|c|c|}
\hline Creatine & $\begin{array}{l}\text { Improves high-intensity } \\
\text { repeated sprint performance. }{ }^{305} \\
\text { Enhances training capacity and } \\
\text { chronic training adaptations } \\
\text { (muscle strength and power } \\
\text { and lean BM). }{ }^{307} 308 \text { May also } \\
\text { support brain function. }{ }^{309}\end{array}$ & $\begin{array}{l}\text { Potential for } 1-2 \mathrm{~kg} \mathrm{BM} \\
\text { increase after creatine } \\
\text { loading. No negative health } \\
\text { effects following appropriate } \\
\text { protocols. }{ }^{310} \\
\text { Falsely increased creatinine } \\
\text { levels. }\end{array}$ \\
\hline
\end{tabular}

Increases muscle creatine stores, increasing the resynthesis of phosphocreatine. ${ }^{311}$ 
Table 3 Continued

\begin{tabular}{|c|c|c|c|c|}
\hline Type of supplement and examples & Use & Concerns & Main mechanisms & Protocol \\
\hline$\beta$-alanine & $\begin{array}{l}\text { Evidence is contradictory: } \\
\text { may improve high-intensity } \\
\text { exercise and repeated sprint } \\
\text { performance. } \\
\text { May enhance training } \\
\text { capacity. }\end{array}$ & $\begin{array}{l}\text { Possible skin rashes and/or } \\
\text { transient paraesthesia (skin } \\
\text { tingling). } \\
\text { A positive correlation } \\
\text { between the magnitude of } \\
\text { muscle carnosine change and } \\
\text { performance benefit remains to } \\
\text { be established. } \\
\text { Sprint training may be more } \\
\text { effective to increase the } \\
\text { buffering capacity of the } \\
\text { muscle. }{ }^{313}\end{array}$ & $\begin{array}{l}\text { Increases muscle carnosine, an } \\
\text { important intracellular buffer. }\end{array}$ & $\begin{array}{l}\text { Daily consumption of } \sim 65 \mathrm{mg} / \\
\mathrm{kg} \mathrm{BM} \text {, ingested via a split- } \\
\text { dose regimen (ie, } 0.8-1.6 \mathrm{~g} \\
\text { every } 3-4 \text { hours) to give up to } \\
6.4 \mathrm{~g} / \text { day over an extended } \\
\text { supplement time frame of } \\
4-12 \text { weeks. Protocol requires } \\
\text { planning alongside training } \\
\text { and match loads. Further } \\
\text { investigation required into } \\
\text { long-term supplementation (ie, } \\
>12 \text { weeks). }\end{array}$ \\
\hline Nitrate & $\begin{array}{l}\text { Limited football-specific } \\
\text { evidence. Improves economy } \\
\text { and endurance exercise } \\
\text { performance }{ }^{305} \text { and football- } \\
\text { specific intermittent exercise } \\
\text { performance in amateur } \\
\text { players. }^{315}\end{array}$ & $\begin{array}{l}\text { Individual response to } \\
\text { supplementation. } \\
\text { Possibility of minor } \\
\text { gastrointestinal upset. } \\
\text { Beetroot juice may discolour } \\
\text { urine. } \\
\text { Performance gains harder } \\
\text { to obtain in highly trained } \\
\text { athletes with well-developed } \\
\text { aerobic capacity. }{ }^{36}\end{array}$ & $\begin{array}{l}\text { Increases tissue nitrite and nitric } \\
\text { oxide, which reduces the oxygen } \\
\text { cost of exercise via enhanced } \\
\text { function of type II muscle fibres } \\
\text { and reduces the ATP cost of force } \\
\text { production. }\end{array}$ & $\begin{array}{l}\text { Protocol: acute performance } \\
\text { benefits are most likely seen } \\
\text { within } 2-3 \text { hours following } \\
\text { a nitrate bolus of } 5-9 \mathrm{mmol} \\
\text { ( } 310-560 \mathrm{mg} \text { ). } \\
\text { Prolonged periods of nitrate } \\
\text { intake ( }>3 \text { days) may also be } \\
\text { beneficial to performance. High } \\
\text { nitrate-containing foods include } \\
\text { leafy green and root vegetables, } \\
\text { including spinach, rocket salad, } \\
\text { celery and beetroot, which may } \\
\text { provide a food first solution for } \\
\text { chronic use. }\end{array}$ \\
\hline
\end{tabular}

In a team sport such as football, where it may be decided by the sports nutritionist or doctor that supplements should be given to a whole team (either the same mix or a different combination per player), extreme caution must be taken by everyone involved. WADA rules state that if three or more players from the same team commit an anti-doping rule violation in the same competition period, the entire team may be disqualified from competition. ${ }^{230}$

\section{How to minimise risk}

The difficulty in quality assurance for dietary supplements is not so much a question of regulation but rather one of enforcing the regulations that are already in place. In almost every country, consumer protection legislation exists to ensure that products on sale are fit for purpose. In the case of supplements, these regulations relate primarily to safety rather than to efficacy. Third-party testing programmes are now in place that allow athletes who use supplements to make choices that will reduce the risk of a positive doping outcome as a result of using contaminated supplements. Examples include: 'Kölner Liste' for Germany, 'Informed Sport' for the UK, 'AFNOR NF V 94-001' for France and 'HASTA' for Australia. These programmes cannot eliminate the risk entirely, but the sensible player will limit the use of supplements and will choose supplements that have been screened for the presence of doping agents by a reputable and independent company. None of the current athlete-centred quality assurance programmes for dietary supplements tests for the presence of the active ingredients. They are focused entirely on the presence of WADA-prohibited substances. Athletes should be aware of this and should not see these schemes as a guarantee that a product is safe and effective to use. Rather, they should be part of a risk reduction strategy. ${ }^{245}$

Where so much is at stake, often for little tangible return, the risks associated with supplements should be considered carefully before use. An expert panel assembled by the Medical and Scientific Commission of the IOC has recently published a decision tree to guide athletes, and those who advise them, through decisions on supplement use. ${ }^{245}$

\section{EXPERT GROUP TOPIC 7: NUTRITION FOR INJURY REHABILITATION}

Nutritional considerations of the injured (elite) athlete have historically been neglected within research related to sports nutrition, which has primarily focused on performance and recovery/adaptation. Nevertheless, while there is much to learn in this space, a collection of laboratory-based studies and elite athlete case studies can be drawn on to devise some nutritional strategies that may be appropriate for the injured footballer.

The high physical demands of the elite game combined with increasingly dynamic movements mean that the risk of injury is also high. When an injury occurs, teams are faced with a unique challenge: to bring a player back as quickly but also as safely as possible. Nutrition may aid in optimising the rehabilitation process and facilitating the desired return.

\section{Injury healing process}

Most injuries rapidly trigger inflammatory processes that initiate wound healing and soft tissue and/or bone repair. Care should be taken to ensure sufficient energy and protein intake and avoid deficiencies in calcium, vitamins D and C, zinc, copper and manganese, all of which may impair the initial healing process. ${ }^{246} 247$ Injuries sustained in football typically occur when performing intense muscular contractions; this is likely to exacerbate the level of systemic and local inflammation after injury (a physiological response assumed to contribute to the subsequent deconditioning of the muscle and/or tendon). ${ }^{248}$ Although a range of 'nutraceuticals' (including phenolic compounds, curcuminoids and n-3 polyunsaturated fatty acids) have been proposed as potential strategies to combat the acute inflammatory process, ${ }^{249}$ direct evidence of their anti-inflammatory effects in humans is lacking. Furthermore, inhibition of postinjury inflammation has 
not been shown to attenuate tissue deconditioning, and could be counterproductive to the healing process. ${ }^{250}{ }^{251}$ Thus, while several important questions remain, the available evidence does not support any nutritional strategies that might limit injuryinduced inflammation.

\section{Minimising effects of deconditioning}

After the initial wound healing response comes rehabilitation, which is possibly of most nutritional relevance to the injured footballer by virtue of the time spent in this phase. Rehabilitation requires a period (anywhere from days to months) of whole body (eg, hospitalisation/bed-rest) or local (eg, limb immobilisation) disuse and/or reduced activity (eg, reduced/absent training load). During this time, rapid soft tissue and bone deconditioning can be expected as a result of mechanical unloading. Skeletal muscle appears to be the tissue most susceptible to disuse, with atrophy and deconditioning (eg, reduced force-generating and oxidative capacities) evident after only a few days. ${ }^{252}$ Bone demineralisation has been reported as early as 1 week into disuse, ${ }^{253}$ and although tendon tissue seems more resistant to disuse atrophy, by $\sim 2$ weeks tendon metabolic and functional properties begin to decline. 254255

Alterations in energy requirements during rehabilitation should be monitored, since shifting to a positive or negative energy balance will modulate aspects of deconditioning. ${ }^{256} 257$ Moreover, a decline in dietary protein intake will accelerate muscle loss irrespective of energy balance. ${ }^{258}$ The rapid development of muscle 'anabolic resistance' to protein intake 239259 requires defined dietary protein recommendations during disuse. Current recommendations for attenuating muscle loss (and regaining muscle) during rehabilitation include: distributing ${ }^{240241}$ adequate amounts $(20-30 \mathrm{~g})^{242} 243$ of leucine-rich $(\geq 2.5 \mathrm{~g}$ per meal) $)^{259}$ protein throughout the day, including pre-sleep. ${ }^{239}$ The efficacy of such an approach is supported by (limited) laboratory data ${ }^{245}$ and applied case studies, ${ }^{90}$ with the resultant recommended daily protein intake being $\geq 1.6 \mathrm{~g} / \mathrm{kg} \mathrm{BM}{ }^{106}$ Emerging data indicate potential roles for specific nutritional compounds in retaining/restoring muscle tissue during rehabilitation (eg, omega-3 fatty acids, ${ }^{260} \beta$-hydroxy- $\beta$-methylbutyrate, ${ }^{261}$ ursolic $\operatorname{acid}^{262}$ ), although these require corroboration in relevant human studies ${ }^{110}$ and therefore cannot be recommended at this time.

The bone collagen protein synthesis rate also increases in response to protein provision, ${ }^{263}$ with an overall positive effect on bone turnover. ${ }^{264}$ Although collagen present in tendon and muscle appears resistant to the anabolic effects of protein, ${ }^{263}$ data indicate that protein supplementation augments tendon hypertrophy during training. ${ }^{265}$ Furthermore, recent work has identified vitamin $\mathrm{C}$ enriched dietary gelatin (which can be included as part of daily protein provision) as a novel strategy to support tendon repair. ${ }^{266}$ Collectively, therefore, available data suggest that nutritional considerations for the rehabilitation of bone and tendon are similar to those for muscle after injury (with respect to energy balance and macronutrient intake).

It must also be recognised that the different phases of injury provide a continuum of altered nutritional needs depending on stage and duration of injury. To date, establishing nutritional guidelines along this continuum, especially with such diverse injuries (in terms of duration, severity and type), are not available. A recent case study measured energy expenditure of $\sim 3100 \mathrm{kcal} /$ day during the first 6 weeks of ACL rehabilitation in an elite Premier League player, ${ }^{159}$ close to that of outfield players in full training. Given the metabolic demand of tissue/wound recovery processes, staying as close to energy balance as possible and thus avoiding drastic reductions in energy intake, is perhaps the most crucial nutritional aspect during rehabilitation. Bearing in mind that the majority of absences from training or competition due to injuries will be $\leq 4$ weeks, ${ }^{267}$ it is prudent to follow the above guidelines while the player is away from normal training, and move back towards nutritional recommendations to support optimal training performance and adaptations (detailed in the section 'Expert group topic 2') as the player moves along the spectrum of return to play.

\section{EXPERT GROUP TOPIC 8: REFEREES}

Refereeing is an intermittent high-intensity activity, and elite football referees are reported to maintain about $80 \%-90 \%$ of their maximum heart rate and $70 \%-80 \%$ of their maximum oxygen uptake during competitive matches ${ }^{268}$ while expending up to $1200 \mathrm{kcal}^{269}{ }^{270}$ Blood lactate concentration may be elevated at crucial moments of the game when repeated sprinting with incomplete recovery occurs. ${ }^{268}{ }^{271}$ Unlike players, referees are not involved in body contact, but they must keep up with the game whatever the imposed tempo, limiting their possibility to compensate for demanding phases of the match. ${ }^{271}$ The amount of high-intensity activity is similar to that reported in midfielders, but referees accumulate a lower overall sprint distance, although with longer bouts during the match. ${ }^{268} 271272$ The physical and physiological demands can impact cognitive performance in decision making. ${ }^{271}$

There is limited literature on the nutritional considerations of match officials. Historically, nutritional recommendations for elite referees were mainly adapted from those of professional football players, without considering the different characteristics (ie, age and body composition) or the particular match/training demands of the two populations. ${ }^{273} \mathrm{~A}$ new publication on the most recent male and female FIFA referee selections (for both the 2014 FIFA men's and 2015 women's World Cups) offers more specific knowledge in this area. ${ }^{274}$ Elite football referees have lower energy needs relative to top-class footballers on MD. During training, total energy and $\mathrm{CHO}$ intakes should be adapted according to the individual training load and increased only around MDs and during periods of intense training or when engaged in occupations with a high-energy demand. Specific nutrient recommendations are generally similar to those for players.

\section{EXPERT GROUP TOPIC 9: JUNIOR PLAYERS}

It is important to highlight some specific considerations and key recommendations for junior elite football players (ie, professional, under 18 years). Nutritional support is key to ensuring that junior players can cope with the demands of training and match play. An additional goal is to ensure life-long buy-in to good nutritional choices as this will help to optimise growth, health, performance, recovery, training adaptations and body composition. The nutritional approach to junior players has the particular challenge of dealing with young people whose bodies are changing as they mature biologically, a process which does not necessarily correlate with chronological age. Young players may have different nutritional needs from those of adults because they are in a phase of growth, and they are more reliant on fat oxidation during exercise. ${ }^{275}$ The RDAs of some essential micronutrients (eg, calcium and phosphorus for both males and females, and iron for males) are higher for junior players than adults, although it should be recognised that good young players are often physically, if not always emotionally, mature. As with 
adult players, emphasising a 'food first' philosophy is essential when educating junior players.

\section{Energy demands}

Football does not overemphasise leanness, but some studies using self-reporting techniques have reported that male $276-279$ and female 120181280281 junior football players may not meet their extra dietary energy needs. A severe chronic energy deficit will impair growth and general health, as well as being detrimental to participation in football training. Conversely, participation in youth sports seems to promote the optimum physical activity level to stimulate growth and bone health when nutritional needs are achieved. ${ }^{282}$ The magnitude energy availability of elite adolescent football players varies and energy deficit appears to be greater on MDs and heavy training days, ${ }^{276}$ which may affect their performance.

Recent research has quantified changes in body composition and resting metabolic rate (RMR) in a cohort of male English Premier League academy soccer players from U12 to U23 age groups. An increase in both fat free mass (FFM) and RMR of $\sim 400 \mathrm{kcal} /$ day was recorded between ages 12 and 16, thus highlighting the requirement to adjust daily energy intake to support growth and maturation. ${ }^{283}$ In addition, a subsequent study demonstrated that daily total energy expenditure (TEE) progressively increases as players transition through the academy pathway, likely a reflection of growth and maturation of key physical parameters as well as increased physical loading: U18 players presented with a TEE $(3586 \pm 487 \mathrm{kcal} / \mathrm{day})$ that was approximately 600 and $700 \mathrm{kcal} /$ day higher than both the U15 $(3029 \pm 262 \mathrm{kcal} / \mathrm{day})$ and U12/13 players $(2859 \pm 265 \mathrm{kcal} / \mathrm{day})$, respectively. ${ }^{284}$ Such differences in TEE is likely due to a combination of differences in anthropometric profile, RMR and physical loading between squads. An important finding is that TEE is comparable to or exceeds that previously reported in adult Premier League soccer players.

As already mentioned (in the section 'Expert group topic 3'), energy deficiency in sport (RED-S) ${ }^{179}$ may affect female junior athletes, and the junior males, with deleterious effects on various nutrition-related functions, such as gastrointestinal, immunological and hormonal functions, as well as on bone development and the risk of developing eating disorders. Players should be evaluated on joining a football academy and monitored periodically thereafter using appropriate charts to examine changes in height-for-weight, weight-for-age, BMI-for-age and body composition.

\section{Macronutrients, micronutrients and supplements}

For specific information on different macronutrients and micronutrients, readers are directed to expert group topic 2 on training day nutrition for all ages.

Daily CHO recommendations by body weight for junior footballers are similar to those of senior players, ${ }^{285}$ with $\mathrm{CHO}$ ingestion spread strategically over the day and in amounts relative to the intensity of training loads, ${ }^{286}$ varying from very low to moderate $(\sim 3-6 \mathrm{~g} / \mathrm{kg} \mathrm{BM})$, and high to upper level $(\sim 6-8 \mathrm{~g} / \mathrm{kg}$ $\mathrm{BM}) .^{2}$ Elite junior football players have been reported to have lower CHO intakes than currently recommended. 287288

Studies on $\mathrm{CHO}$ loading in young players are lacking, but intake should be sufficient to optimise glycogen stores and deliver glucose as energy for repeated high-intensity sprints and performance. During long training sessions and matches, some $\mathrm{CHO}$ intake may be favourable. Active boys consuming $\mathrm{CHO}(60 \mathrm{~g} / \mathrm{L})$ beverages shifted their relative energy reliance to the exogenous intake in both temperate 289 and hot $\left(38^{\circ} \mathrm{C}\right)^{290}$ conditions. Sparing endogenous $\mathrm{CHO}$ reserves could help delay fatigue and improve performance.

Protein needs increase during adolescence and with intensive football training, so a daily intake of up to $1.6 \mathrm{~g} / \mathrm{kg} \mathrm{BM}$ for junior players would be appropriate. ${ }^{285}$ Such extra protein intake is easily achievable from dietary sources, without the need for supplements. One study has recently shown that junior male footballers met or exceeded the dietary protein recommendations, although their distribution of protein intake over the day was not optimal. ${ }^{288}$ The relative distribution of protein ingestion was, as in adults, skewed from dinner (highest) to lunch to breakfast (lowest). Recommendations should emphasise balanced distribution of protein in meals to optimise muscle development. Players, especially those undertaking restrictive or vegetarian diets, ${ }^{285}$ should be individually evaluated to verify that they are achieving a sufficient protein intake.

Daily energy intake from fat should be $25 \%-35 \%$ of total energy intake and cholesterol intake should not exceed $300 \mathrm{mg} .{ }^{291}$ A higher absolute intake for junior players should only be as a result of increased energy demands, and there is no evidence for a greater dietary need compared with their non-athletic peers. Due to concerns about becoming overweight, some junior players restrict dietary fats, which may cause micronutrient deficiencies including iron, calcium and vitamins $\mathrm{A}, \mathrm{D}, \mathrm{E}$ and $\mathrm{K} .{ }^{111}$ Milk provides a good amount of calcium $(\sim 300 \mathrm{mg} / 250 \mathrm{~mL}$ serving), which is critical for bone mineral growth and health. Adolescent athletes' daily calcium intake should be 1200-1500 mg (compared with $700 \mathrm{mg}$ RDA for adults). ${ }^{285}$ A 7 -year prospective study ${ }^{292}$ showed that inadequate vitamin D intake increased the risk of stress fractures among adolescent girls, especially those involved in daily high-impact activities. Overall, recommendations for adolescents vary from 400 to $600 \mathrm{IU} /$ day. Assessment of bone health (densitometry) and vitamin D status may be useful, particularly in those with previous injuries or a slighter build, since collisions and intense efforts are frequent in football.

Iron requirements are also high during growth, especially in girls following menarche, and iron deficiency may impair high-intensity and endurance performance. To achieve the daily recommendations according to age $(8 \mathrm{mg}$ from 9 to 13 years and $11-15 \mathrm{mg}$ from 14 to 18 years, for boys and girls), players should ingest iron-containing foods with vitamin $\mathrm{C}$ and limit their intake of absorption inhibitors (eg, tea and coffee). It is important to examine the iron status of junior football players regularly by measuring their serum ferritin and blood haemoglobin concentrations. Unless iron deficiency is confirmed, iron supplementation is not beneficial.

Mild (1\%-2\% BM loss) hypohydration has been shown to impair high-intensity cycling ${ }^{293}$ and basketball ${ }^{294}$ performance in active and athletic boys. A concern when playing in the heat is further hypohydration, which exacerbates hyperthermia and the risk of exertional heat illness. ${ }^{295}$ Challenges to hydration status include tournament play-offs involving successive games, with insufficient time for recovery. Junior players have been reported to arrive for training sessions and competitions already hypohydrated, as indicated by urinary markers. ${ }^{296-298}$

\section{Dietary supplements}

Due to a lack of benefit/safety evidence, general use of dietary supplements should be restricted, and a sports nutritionist 
or team doctor should evaluate the specific needs ${ }^{299}$ of the individual players, the team and local policies. Many adolescents consume supplements, often as a result of mass media and misinformation provided by suppliers. ${ }^{299}$ Parents and coaches may also have erroneous beliefs and wrongly supply their children and/or athletes with supplements. ${ }^{300}$

In summary, well-planned nutritional strategies may help junior football players to achieve a successful athletic performance and to optimise their recovery, growth, maturation and body composition, avoid injuries and achieve a long athletic and healthy lifestyle.

\section{CONCLUSION}

Over the past decade, the game of football has changed, both physically and technically. At the same time, football-specific research in sports nutrition has expanded greatly. To reflect these changes, UEFA commissioned an expert group, including applied researchers and field-based practitioners, to provide an overview and narrative synthesis of the current evidence on a range of topics related to the optimisation of the health and performance of elite players and officials in order to guide practical recommendations and guide future research. We share a series of updates on scientific knowledge and where possible and appropriate provided a critical narrative synthesis.

Specifically we have covered (1) MD nutrition, (2) training day nutrition, (3) body composition, (4) stressful environments and travel, (5) cultural diversity and dietary considerations, (6) dietary supplements, (7) rehabilitation, (8) referees and (9) junior high-level players.

Our narrative synthesis and critical appraisal takes into account the diversity of the footballing community, including both male and female players, outfield players and goalkeepers and match officials. We have outlined how the type, quantity and timing of foods, fluids and supplements can influence the performance and recovery of players during and between matches, while also recognising the cultural significance of food and nutrition as part of this truly global sport.

With this expert statement, we hope that these scientific underpinnings can inform practitioners to drive a set of clear practical recommendations in their own setting. In addition, we will highlight the key areas for future research to be targeted in order to improve confidence in recommendations and shed light on emerging areas within football nutrition. The reader should note that this expert group statement represents level 5 (expert opinion) evidence.

\section{Author affiliations}

${ }^{1}$ Intra Performance Group, London, UK

2Performance and Research Team, Arsenal Football Club, London, UK

${ }^{3}$ School of Medicine, St Andrews University, St Andrews, UK

${ }^{4}$ School of Sports Exercise and Health Sciences, Loughborough University, Loughborough, UK

${ }^{5}$ Faculty of Health, University of Technology, Sydney, New South Wales, Australia ${ }^{6}$ New England Patriots, Foxboro, MA, USA

${ }^{7}$ MySport Science, Birmingham, UK

${ }^{8}$ Research Institute for Sport and Exercise Sciences, Liverpool John Moores University, Liverpool, UK

${ }^{9}$ Kinesiology, McMaster University, Hamilton, Ontario, Canada

${ }^{10}$ Human Performance Laboratory, University of Connecticut, Storrs, CT, USA

${ }^{11}$ Mary MacKillop Institute for Health Research, Australian Catholic University, Melbourne VIC, Australia

${ }^{12}$ Medical Department, Football Federation Australia, Sydney, New South Wales, Australia

${ }^{13}$ Department of Human Nutrition, Foods, and Exercise, Virginia Tech, Blacksburg, VA, USA

${ }^{14}$ Athlete Care and Performance, Monumental Sports \& Entertainment, Washington, DC, USA
${ }^{15}$ Federal University of Rio Grande do Sul, Porto Alegre, Brazil

${ }^{16}$ PepsiCo Life Sciences, Global R\&D, Gatorade Sports Science Institute, Birmingham, UK

${ }^{17}$ Department of Sports Medicine, The Norwegian School of Sport Sciences, Oslo, Norway

${ }^{18}$ Department of Sport and Health Sciences, College of Life and Environmental

Sciences, University of Exeter, Exeter, UK

${ }^{19}$ Mexican Football Federation, Mexico City, Mexico

${ }^{20} \mathrm{FC}$ Barcelona, Barcelona, Spain

${ }^{21}$ Dutch Olympic Team, Amsterdam, Netherlands

${ }^{22}$ Research and Human Performance Lab, Schulthess Clinic, Zurich, Switzerland

${ }^{23}$ University of Rome Tor Vergata, Rome, Italy

${ }^{24}$ Technical Department, Italian Football Federation (FIGC), Florence, Italy

${ }^{25}$ Italian Football Referees Association, Bologna, Italy

${ }^{26}$ Technical Directorate, Football Association, Burton upon Trent, UK

${ }^{27}$ Medical Committee, UEFA, Nyon, Switzerland

${ }^{28}$ Medical Centre of Excelence, Schulthess Clinic, Zurich, Switzerland

${ }^{29}$ Center for Preventive Doping Research, German Sport University Cologne, Cologne, Germany

${ }^{30}$ Institute of Sports and Preventive Medicine, Saarland University, Saarbrücken, Germany

${ }^{31}$ Medical \& Anti-doping, UEFA, Nyon, Switzerland

${ }^{32}$ Sport, Exercise and Health Sciences, School of Applied Sciences, Edinburgh Napier University, Edinburgh, UK

Correction notice This article has been corrected since it published Online First. A spelling error has been corrected within the first paragraph of the heading EXPERT GROUP TOPIC 3: BODY COMPOSITION.

Twitter James Collins @JamesCollinsPN, Michael Gleeson @profmikegleeson, Johann Bilsborough @jbils1972, Asker Jeukendrup @jeukendrup, S M Phillips @mackinprof, Julien Louis @JInlouis, lan Rollo @Rollo_I, Jorunn Sundgot-Borgen @Jorunn_SB, Charlotte M Cowie @drccowie and Alan McCall @Alan_McCall_

Contributors The main steering committee consisted of JC, RJM, MG, JB and AMcC. All authors contributed to the full manuscript. The authors were assigned a specific topic to write fully and then all authors reviewed and provided input for final version. Specifically AJ—match-day nutrition, JPM and LB — training day nutrition, MG—-staying healthy, GLC - micronutrients, JB-body composition, LA, RD—stressful environments, JC and TM — cultural and dietary differences, RJM and $J L$-supplements, BW-rehabilitation nutrition, CC and MB - referees, FM-junior players, JS-B and EL-M - key differences between male and female players. Football nutrition practitioners/heads of performance GD, DM, BB, PR and AL reviewed all stages of the planning and written manuscript to ensure ecological validity to the practical setting. The UEFA Medical Committee members TM, MV, MD'H, HG, CC and NP were involved in planning stages as the governing body commissioning the experts. They were additionally involved in all stages of the manuscript to review and provide editing suggestions and comments. AMcC and JC were the main coordinators during the process.

Funding The authors have not declared a specific grant for this research from any funding agency in the public, commercial or not-for-profit sectors.

Competing interests $\mathrm{JC}$ has received payment for sports nutrition consultancy work with Arsenal Football Club, England Football Association and France Football Federation. Through his consultancy he also receives payment for nutrition services with individuals and corporate organisations. He is author of a book (The Energy Plan) for which he receives payment from Penguin Random House. He has written articles for BBC Good Food for which he has received payment. He co-authored an article in 2014 and presented at European College of Sports Sciences in 2019 for The Gatorade Sports Science Institute, for which he received honoraria. He has received travel and accommodation expenses to speak at conferences over the past 5 years including; UEFA Medical Symposium, Isokinetic Football Medicine Strategies, Swedish Sports Medicine Congress and International Sport \& Exercise Nutrition Conference. He is a council member and past president of The Royal Society of Medicine's Food \& Health Forum. He received from UEFA the cost of flight and accommodation to attend an Expert Group Meeting with the UEFA Medical Committee in Brussels, Belgium, to discuss preparation of this manuscript." He did not receive any other form of financial support directly related to this manuscript. RM holds an honorary (unpaid) professorship at the School of Medicine, St Andrews University, Scotland. He holds visiting (unpaid) professorships at Stirling University and at the Chinese University of Hong Kong. He is co-author of two books published by Oxford University Press (Biochemistry of Exercise and Training; The Biochemical Basis of Sports Performance) for which he receives royalties. He is Program Director on the IOC Diploma programs in Sports Medicine, Sports Nutrition and Sports Physical Therapies, for which he receives honoraria and additionally contributes lectures to those programs, for which he has received honoraria. He was a member of the Expert Scientific Committee of the IOC Medical and Scientific Commission. This position was unpaid, but travel to meetings and accommodation were provided. He contributed a scientific review to a meeting of the Gatorade Sports Science Institute 
in Texas in March 2019: travel and accommodation were paid and an honorarium was received for participation in the meeting and for preparation of a summary paper for publication in the SSI Sports Science Exchange. He participated in an ACSM online podcast in 2019 for which an honorarium was received. He participated in a sports medicine education meeting organised by the Medical Committee of the German Football Federation in Frankfurt in January 2020: travel expenses and an honorarium were paid. He has participated in numerous other international sports nutrition symposia between 2015 and the present for which travel and accommodation were provided. He received from UEFA the cost of flight and accommodation to attend an Expert Group Meeting with the UEFA Medical Committee in Brussels, Belgium, to discuss preparation of this manuscript." He did not receive any other form of financial support directly related to this manuscript. MG is co-author of two books published by Oxford University Press (Biochemistry of Exercise and Training; The Biochemical Basis of Sports Performance) for which he receives royalties. He is also co-author of 3 other books; one published by Human Kinetics (Sport Nutrition), one published by Routledge (Exercise Immunology) and the other by Meyer \& Meyer Sport (Eat, Move, Sleep, Repeat; Beating Type 2 Diabetes) all of which he receives royalties for. He has contributed to several recorded lectures for which he received honoraniums for; 2020 to the IOC Diploma program Sports Nutrition, 2020 to the Nutrition Society Training Academy, 2020 to the My Sport Science Academy. He was a member of the IOC Expert Scientific Group on training load and illness/injury in 2015. This position was unpaid, but travel to a meeting and accommodation were provided. Other international symposia were attended as speaker where honorarium was paid plus travel and accommodation; Japan, 2016, London 2015, Barcelona 2015, Vienna, 2015. Mike also contributed a scientific review on nutrition, exercise and immune function for a sport nutrition company, NutritionX, in 2020 for which an honorarium was received. He has received complimentary tickets for Leicester City FC football matches for occasional nutrition consultancy advice but no honoraria were received. He has spoken at a number of other conferences, symposia and other events within the last five years: travel and accommodation were provided for most of these, but no record has been kept. He did not receive any form of financial support directly related to this manuscript. JB has presented at the Arsenal Sports \& Exercise Medicine conference in London, UK, where travel and accommodation were paid by Arsenal FC. He has co-authored two chapters in the book, 'The Science and Application of High-intensity interval training (HIIT) with no honorarium nor any royalties received. He did not receive any form of financial support directly related to this manuscript. AJ holds a visiting professorship at the Loughborough University, UK and is director of mysportscience. He is also co-founder and CEO of CORE Nutrition planning. He is author of a book sport nutrition by Human Kinetics for which he receives royalties. $\mathrm{He}$ is board member of the IOC Diploma programs in Sports Medicine. Asker worked as a consultant for the Dutch Olympic Committee NOC*NSF, Red Bull Leipzig, FC Barcelona, PSV Eindhoven, Athletic Club de Bilbao, US Soccer, Red Bull Athlete Performance Center, Jumbo Visma Pro cycling, Universidad d'Europea de Madrid, University of Barcelona, CAR, VIC University, Hiddit, SinSeb, Enervit, Volanthen, Friesland Campina, Nutrition Society, Clif, Snelle Jelle, Jumbo Supermarkten, PepsiCo, Unit Nutrition, BF Eventos, Mexican sports nutrition federation and the Turkish sports nutrition federation. Travel expenses and an honorarium were paid. He has participated in numerous other international sports nutrition symposia between 2015 and the present for which travel and accommodation were provided. He did not receive any form of financial support directly related to this manuscript. JM has received research grants from UEFA, Science in Sport, Lucozade Ribena Suntory, GlaxoSmithKline, Liverpool Football Club, Everton Football Club, British Horseracing Authority, Racing Welfare Foundation, Port Adelaide FC, English Institute of Sport and MuscleSound. He has received paid consultancy for Liverpool Football Club, Team Sky, Healthspan Elite, FA Premier League, Irish Football Association, The Football Association, Rangers FC and Science in Sport. He is the current Director of Performance Solutions for Science in Sport. He is the co-author of the textbook Biochemistry for Sport and Exercise Metabolism and receives annula royalties form Wiley. He has received travel and accommodation costs to speak at over 50 conferences in the last 5 years. He did not receive any form of financial support directly related to this manuscript. SP reports personal fees from Enhanced Recovery (donated to charity), equity from Exerkine (donated to charity), grants from Canadian Institutes of Health Research, grants from National Science and Engineering Council, personal fees (Travel and Honorarium, 2018) from US National Dairy Council, personal fees from US Dairy Export Council (Traval and Honorarium, 2019), persona fees from Leprino Foods (2017), personal fees from Agropur (2018), grants from Alliance for Potato Research and Education, grants from US National Dairy Council, outside the submitted work; In addition, Dr. Phillips has a patent 3052324 (Canadian) issued to Exerkine, a patent 16/182891 (US) pending to Exerkine, and a patent 2018157258 (Worldwide) pending to Exerkine. He did not receive any form of financial support directly related to this manuscript. LA received honoraria as an occasional consultant and reimbursement for travel expenses from the Drinking Water Research Foundation, Alexandria, VA, USA and from Danone Nutricia Research, France. He previously received research grant funding from both organizations. He formerly served as the elected President of the American College of Sports Medicine (unpaid), 2015-2016. He received honoraria and reimbursement of travel expenses from five universities and the Texas Regional Chapter of the
American College of Sports Medicine during a speaking tour in 2018. He presently serves as a member of the Medical \& Science Advisory Board, Korey Stringer Institute, University of Connecticut, USA (unpaid). Professor Armstrong received no financial support for participating in this manuscript. LB is an author or editor of textbooks on sports nutrition for which she receives royalties. She is a Program Director and contributor to the IOC Diploma programs in Sports Nutrition for which she receives honoraria. Prior to June 2020 she was Head of Sports Nutrition and Chief of Nutrition Strategy at the Australian Institute of Sport, where her representation at numerous international sports nutrition symposia and workshops was generally undertaken within her job description and any travel reimbursements and honoria were provided to the AIS. Presentations during the period of 2015-2020 in which the activity and its support were undertaken as private consultancy include: 2015 Berlin Marathon powerbar conference; 2019 ACSM meeting and preconference GSSI workshop (supported by the International Association of Athletics Federation and Gatorade); 2019 Northern Ireland Workshop on Sports Nutrition (supported by Dairy Council Northern Ireland) and the 2016 SCAN conference and 2019 FNCE conference (supported by the Academy of Nutrition and Dietetics). She has received a research grant from the Alliance of Potato Research and Education. She did not receive any form of financial support directly related to this manuscript. GC has previously received payment for nutrition consultancy at Everton, Nottingham Forest and West Bromwich Albion and Aston Villa Football clubs, Munster Rugby, England Rugby The Lawn Tennis Association The Football Association, The English Institute of Sport and The Saudi Arabian Olympic Association and The European Tour Golf. He currently advises HealthSpan Elite and NutritionX for which he receives an honorarium and in the past has advised GetBuzzing bars. GC has spoken on several occasions for GSSI and produced articles for their exchange series for which he received an honorarium. He has spoken at a number of other conferences, symposia and other events within the last five years: travel and accommodation were provided for most of these, but no record has been kept. GC currently or has previous received research grants from the MRC, BSSRC, GSK, Sirtris, Research into Ageing, Aliment Nutrition, Naturecan, HH Sheikh Mansour Bin Zayad Al Nahyan Global Arabian Horse Flat Racing Festival, The Racing Foundation, The British Horse Racing Association, The Rugby Football Union, The Lawn Tennis Association, Newport Gwent Dragons, Gloucester Rugby, Everton FC, Aston Villa FC. GC has delivered guest lectures for the IOC diploma in Sport Nutrition and The Football Science Institute for which he received an honorarium. GC has previously performed consultancy work for Callaway Golf and Quooker Taps. He did not receive any form of financial support directly related to this manuscript. RD receives is Joint Head of Research \& Development at Football Federation Australia and is paid for this role. He has received travel and accommodation funding to speak / present at several international congress, including; the Football Science Institute, Football Federation Australia, Tennis Australia, Brazil National Football Federation, UFSC Brazil, Canadian Institute of Sport, Bristol City FC and UdS Germany. He is not affiliated or received any travel, accommodation, funding from any nutrition company in the last 10 years. He did not receive any form of financial support directly related to this manuscript. EL-M is author of a book published by Human Kinetics (Plant-Based Sports Nutrition: Expert Fueling Strategies for Training, Recovery, and Performance) for which she receives royalties. She was a member of the Dietary Supplements and the High-Performance Athlete Expert Scientific Committee of the IOC Medical and Scientific Commission in 2017; this committee assignment was unpaid, but travel to the group meeting and accommodation were provided. She contributed scientific presentations to a meeting of the Gatorade Sports Science Institute in Florida in Oct 2017 and Gatorade at NFL Combine in Feb 2020: travel and accommodation were paid and an honorarium was received for participations at both meetings and for preparation of a summary paper for publication in the SSI Sports Science Exchange in 2018. She presented at a Danone Essential Dairy and Plant-Based Proteins Board Meeting in New York in July in 2019 for which travel, accommodations and an honorarium were paid. She has participated in numerous other national nutrition and medical conferences between 2015 and the present for which travel and accommodation and typically an honorarium were received. She did not receive any form of financial support directly related to this manuscript. JL has received payment for sport nutrition consultancy work with French Football Federation, Liverpool Football Club, Lille Football Club, Paris-Dakar association. He has received travel/accommodation funding and honorariums to speak / present at several national/international conferences between 2015 to present) including: Research day of the Dairy Council UK; European College of Sport and Exercise Physicians, Paris, France; International conference of Sports Physiotherapy, Kuala Lumpur, Malaysia; French Football Federation congress for S\&C coaches, Paris; congress of the Mexican Nutrition Society, Guadalajara; and congress of the Swiss Nutrition society, Nottwil. He has contributed to several recorded lectures for which he received honorariums for the IOPN Diploma, London, UK. He co-supervised a PhD project funded by a nutrition company (Lactalis, Laval, France). He did not receive any form of financial support directly related to this manuscript. DM has no conflicts to disclose. He did not receive any form of financial support directly related to this manuscript. FM is the main editor of a book published by CRC Press, Taylor \& Francis Group (Fluid Balance, Hydration and Athletic Performance) for which she receives royalties. She hold a visiting professor position at the Human Movement Graduate Program from 2018 to 2020 (unpaid) at the Federal University of Rio Grande do Sul. She did not receive any form of financial 
support directly related to this manuscript. IR is an employee of the Gatorade Sports Science Institute (GSSI), a division of PepsiCo, Incorporated. The views expressed in this article are those of the authors and do not necessarily reflect the position or policy of PepsiCo, Incorporated. Ian leads the FC Barcelona, innovation hub certificate in sports nutrition, he is co-author on the FC Barcelona Sports Nutrition guide for Football and co-organises the FCB conference in Sports nutrition, all as part of his role with GSSI. Ian co-authored a chapter on nutrition in the book "Elite Soccer Players" with no honorarium nor any royalties received. He not receive any form of financial support directly related to this manuscript. JSB holds a professorship at the Norwegian School of Sports Science in Oslo Norway. She receives research grants from The Norwegian Woman's Public Health Association, the Norwegian Extra Foundation for Health and Rehabilitation, The Norwegian Association of Youth Mental Health, and the Dam Foundation and TINE SA. She has contributed with lectures for the IOC Diploma programs in Sports Medicine and Sports Nutrition and receives honoraria for about one lecture per year. She was a member of the Expert Scientific Committee of the IOC Medical and Scientific Commission. She has also been a member in IOC working group (position papers). These positions were unpaid, but travel to meetings and accommodation were provided. She is also an International trustee (ACSM) and Vice president in Nordic Eating Disorder Society. These positions are unpaid, but travel to meetings and accommodation are provided. BW Received honorarium for consultancy with Nutricia. BW is the editor of one book (carnitine metabolism and human nutrition) published by CRC press for which he receives royalties. He has made lecture contributions to the International Society for Sports and Exercise Conference (ISENC), Nutrition Society, European Society for Parenteral and Enteral Nutrition (ESPEN) and Physiological Society which were unpaid for which he received expenses. He has received travel and expenses for an organised symposium (by Ketchum PR, US) at American Society for Nutrition (ASN) and the Reducetarian Conference. He has received payments from various UK universities for external examining with the last 5 years. He did not receive any form of financial support directly related to this manuscript. BB is co-author of two books, one published by McGrawHill (Nutrición Deportiva) for which she receives royalties and another one published by Organización Panamericana de la Salud (La Receta de los Campeones) for which she received royalties in the past. She is Program Director on the FMND-Nutrinfo Curse in Sports Nutrition, for which she receives honoraria and additionally contributes with one lectures to these program, for which she has received honoraria. She has participated in numerous international sports nutrition symposia between 2011 and the present for which travel and accommodation were paid by The Mexican Football Federation. She advises The Coca Cola Company for issues related to their Sport Beverage Powerade since 2012 for which she receives honoraria. She did not receive any form of financial support directly related to this manuscript. GD is head of performance for CF Real Madrid. He holds visiting (unpaid) professorships at Liverpool John Moores University He previously worked for the French Football Federation, Lille FC and the universities of Artois and Lille. He is co-author of a book on training methodology and performance (2007, three chapters (monitoring fatigue and recovery, Thieme eds, 2017; Targeted Systems of the Body for Training in Football Science, Human Kinetics, 2016; Boosting Aerobic Performance in High-Performance training for Sports, Human Kinetics, 2016), for which he received royalties. He has lectured for Aspetar twice $(2013,2016)$ recovery and nutrition courses for which he has received travel expenses, accommodation and an honorarium. He has spoken at 33 international conferences on sports science and football for which he has received travel expenses and accommodation, no honorariums have been received. He did not receive any form of financial support directly related to this manuscript. MAL: Toña is Professor of the Human Nutrition and Dietetics degree at the University of Barcelona and Nutritional Advisor of FCB. She is involved in clinical consultation and advice to competitive athletes and she did not receive any form of financial support directly related to this manuscript. PR is currently employed by the Dutch Olympic Team. He was formerly employed by AFC Ajax Amsterdam. He is owner of PR Sportvoedingsadvies. Through his consultancy he also receives payment for nutrition services with individuals and corporate organisations. He co-authored an article for The Gatorade Sports Science Institute, for which he received honoraria. He received honoraria as an invited speaker for the Barça Sport Nutrition Conference and FrieslandCampina Institute congress "sport en voeding". He did not receive any form of financial support directly related to this manuscript. MB has received travel and accommodation funding (from the organizers and/or the Schulthess Clinic) to speak/present at several international congress between 2015 to present, including: the Isokinetic Football Medicine Strategies Conferences (2015-2019, London \& Barcelona), Team Concept Conference 2016 (Las Vegas), the IOC World Conference 2017, the World Conference of Sports Physical Therapy (Belfast 2017, Vancouver 2019), the Salzburg Sports PT Congress 2019, the ACL Consensus Meeting (Pittsburgh 2019), the International Conference on Football Refereeing (Lisbon 2019), the International Society of Hip Arthroscopy Physiotherapy Meeting (Madrid 2019). As a member of F-MARC (2002- 2016) he received compensation from FIFA for his work during this time, but no other compensations or grants have been received. Between 2015 and 2019 he has authored/co-authored nine book chapters (football medicine, sports medicine) with no honorarium nor any royalties received. He did not receive any form of financial support directly related to this manuscript. CC: Since 2007 I have been invited in international conference/seminar by FIFA and
UEFA for lectures on refereeing receiving no honorary but having paid travels, accommodation and daily expenses. I did not receive any form of payment for the contribution to this manuscript. CC has not received any honorarium from any company in the last 5 years. She is employed by the Football Association and has a private medical practice. She is member of the UEFA medical committee and have paid expenses (travel \& accommodation) for UEFA medical committee meetings. She received from UEFA the cost of flight and accommodation to attend an Expert Group Meeting with the UEFA Medical Committee in Brussels, Belgium, to discuss preparation of this manuscript." She did not receive any other form of financial support directly related to this manuscript. MD: The travel to attend an Expert Group Meeting with the UEFA Medical Committee in Brussels, Belgium, to discuss preparation of this manuscript was paid by UEFA. No other conflicts to declare. He did not receive any other form of financial support directly related to this manuscript. $\mathrm{HG}$ has received honorarium and reimbursement of travel and accommodation expenses for expert statements in doping cases in connection with nutritional supplements for several federations and anti-doping organisations, including UEFA and FIFA and several National Anti-Doping Agencies. He has received daily fees and reimbursement of travel and accommodation expenses for his participation in WADA expert groups for the athlete biological passport. He has received honorarium and reimbursement of travel and accommodation expenses for lectures about doping risks of nutritional supplements in congresses of several medical societies. He has received reimbursement of travel and accommodation expenses for his participation at the IOC consensus conference about nutritional supplements. The travel to attend an Expert Group Meeting with the UEFA Medical Committee in Brussels, Belgium, to discuss preparation of this manuscript was paid by UEFA. No other conflicts to declare. He did not receive any other form of financial support directly related to this manuscript. TM has never received any royalties or fees from nutritional companies or other relevant sources. For none of his publications has he ever received any financial compensation except for one article about the management of infectious diseases in the Aspetar Sports Medicine Journal. He received from UEFA the cost of flight and accommodation to attend an Expert Group Meeting with the UEFA Medical Committee in Brussels, Belgium, to discuss preparation of this manuscript." He did not receive any other form of financial support directly related to this manuscript. NP: The travel to attend an Expert Group Meeting with the UEFA Medical Committee in Brussels, Belgium, to discuss preparation of this manuscript was paid by UEFA. No other conflicts to declare. She did not receive any other form of financial support directly related to this manuscript. MV: The travel to attend an Expert Group Meeting with the UEFA Medical Committee in Brussels, Belgium, to discuss preparation of this manuscript was paid by UEFA. No other conflicts to declare. He did not receive any other form of financial support directly related to this manuscript. AM has received a grant from FIFA to investigate health and performance of footballers during the transition from club to national teams. He has received travel and accommodation funding to speak / present at several international congress between 2015 to present), including; the Isokinetic Football Medicine Strategies Conference (London and Barcelona), KNVB national federation, Danish SportsKongress, Denmark, Sportsfisio congress, Switzerland, The Barça Innovation Hub, Barcelona, Spain. Oslo Sports Trauma Research Group, Oslo, Norway. Mapei Research Centre, Bergamo, Italy. Brazil National Football Federation, Rio, Brazil, French Football Federation, Paris, France. He is not affiliated or received any travel, accommodation, funding from any nutrition company. He also received consultancy fee from the French Football Federation for injury prevention recommendations for the 2018 FIFA World Cup. He received from UEFA the cost of flight and accommodation to attend an Expert Group Meeting with the UEFA Medical Committee in Brussels, Belgium, to discuss preparation of this manuscript." He did not receive any other form of financial support directly related to this manuscript.

Patient consent for publication Not required.

Provenance and peer review Not commissioned; externally peer reviewed. Data availability statement There are no data in this work.

\section{ORCID iDs}

S M Phillips http://orcid.org/0000-0002-1956-4098

Louise M Burke http://orcid.org/0000-0001-8866-5637

Graeme L Close http://orcid.org/0000-0002-7210-9553

Rob Duffield http://orcid.org/0000-0002-5641-1314

Julien Louis http://orcid.org/0000-0002-9109-0958

Flavia Meyer http://orcid.org/0000-0002-7290-4354

Jorunn Sundgot-Borgen http://orcid.org/0000-0002-1149-0442

Gregory Dupont http://orcid.org/0000-0001-8057-882X

Carlo Castagna http://orcid.org/0000-0002-8320-6404

Tim Meyer http://orcid.org/0000-0003-3425-4546

Alan McCall http://orcid.org/0000-0003-3780-8153

\section{REFERENCES}

1 Nutrition for football: the FIFA/F-MARC consensus conference. J Sports Sci 2006;24:663-4. 
2 Thomas DT, Erdman KA, Burke LM. American College of sports medicine joint position statement. nutrition and athletic performance. Med Sci Sports Exerc 2016;48:543-68

3 Collins J, McCall A, Bilsborough J, et al. Football nutrition: time for a new consensus? Br J Sports Med 2017;51): :1577-8.

4 Burke LM. Communicating sports science in the age of the Twittersphere. Int J Sport Nutr Exerc Metab 2017;27:1-5.

5 Barnes C, Archer DT, Hogg B, et al. The evolution of physical and technical performance parameters in the English premier League. Int I Sports Med 2014;35:1095-100.

6 Bush M, Barnes C, Archer DT, et al. Evolution of match performance parameters for various playing positions in the English premier League. Hum Mov Sci 2015;39:1-11.

7 Bengtsson $H$, Ekstrand J, Hägglund M. Muscle injury rates in professional football increase with fixture congestion: an 11-year follow-up of the UEFA champions League injury study. Br J Sports Med 2013;47:743-7.

8 Dupont G, Nedelec M, McCall A, et al. Effect of 2 soccer matches in a week on physical performance and injury rate. Am J Sports Med 2010;38:1752-8.

9 FIFA. Why is football the world game? 2008. Available: https://www.fifa.com live-scores $/$ news $/ y=2008 / \mathrm{m}=7 /$ news =why-football-the-global-game- 830125 .html [Accessed 12 Sep 2019].

10 Coutts AJ. Challenges in developing evidence-based practice in high-performance sport. Int J Sports Physiol Perform 2017;12:717-8.

11 Archer E, Lavie CJ, Hill JO. The failure to measure dietary intake engendered a Fictional discourse on Diet-Disease relations. Front Nutr 2018;5:105

12 Burke LM, Castell LM, Casa DJ, et al. International association of athletics Federations consensus statement 2019: nutrition for athletics. Int J Sport Nutr Exerc Metab 2019:29:73-84.

13 Bangsbo J, Mohr M, Krustrup P. Physical and metabolic demands of training and match-play in the elite football player. J Sports Sci 2006;24:665-74.

14 Bangsbo J, Nørregaard L, Thorsø F. Activity profile of competition soccer. Can J Sport Sci 1991;16:110-6.

15 Ferrauti A, HT G, Merheim G, et al. Indirekte Kalorimetrie Im Fußball indirect calorimetry in a soccer game. Deutsche Zeitschrift für Sportmedizin 2006;57:142-6.

16 Anderson L, Orme P, Naughton RJ, et al. Energy intake and expenditure of professional soccer players of the English premier League: evidence of carbohydrate Periodization. Int J Sport Nutr Exerc Metab 2017;27:228-38.

17 White A, Hills SP, Cooke CB, et al. Match-Play and performance test responses of soccer Goalkeepers: a review of current literature. Sports Med 2018;48:2497-516.

18 Datson N, Drust B, Weston M, et al. Match physical performance of elite female soccer players during international competition. J Strength Cond Res 2017;31:2379-87.

19 Murray NB, Gabbett TJ, Townshend AD, et al. Individual and combined effects of acute and chronic running loads on injury risk in elite Australian footballers. Scand J Med Sci Sports 2017;27:990-8.

20 Anderson L, Orme P, Di Michele R, et al. Quantification of training load during one-, two- and three-game week schedules in professional soccer players from the English premier League: implications for carbohydrate periodisation. J Sports Sc 2016:34:1250-9.

21 Leatt PB, Jacobs I. Effect of glucose polymer ingestion on glycogen depletion during a soccer match. Can J Sport Sci 1989;14:112-6.

22 Krustrup P, Mohr M, Steensberg A, et al. Muscle and blood metabolites during a soccer game: implications for sprint performance. Med Sci Sports Exerc 2006;38:1165-74.

23 Saltin B. Metabolic fundamentals in exercise. Med Sci Sports 1973;5:137-46.

24 Shirreffs SM, Sawka MN, Stone M. Water and electrolyte needs for football training and match-play. J Sports Sci 2006;24:699-707.

25 Ekblom B. Applied physiology of soccer. Sports Med 1986;3:50-60.

26 Shirreffs SM, Aragon-Vargas LF, Chamorro M, et al. The sweating response of elite professional soccer players to training in the heat. Int J Sports Med 2005;26:90-5.

27 Cheuvront SN, Ely BR, Kenefick RW, et al. Biological variation and diagnostic accuracy of dehydration assessment markers. Am J Clin Nutr 2010;92:565-73.

28 Armstrong LE, Ganio MS, Klau JF, et al. Novel hydration assessment techniques employing thirst and a water intake challenge in healthy men. App/ Physiol Nutr Metab 2014;39:138-44

29 Armstrong LE, Pumerantz AC, Fiala KA, et al. Human hydration indices: acute and longitudinal reference values. Int J Sport Nutr Exerc Metab 2010;20:145-53.

30 Armstrong LE, Soto JA, Hacker FT, et al. Urinary indices during dehydration, exercise, and rehydration. Int J Sport Nutr 1998;8:345-55.

31 Kenefick RW, Cheuvront SN. Hydration for recreational sport and physical activity. Nutr Rev 2012;70 Suppl 2:S137-42.

32 Noakes TD. Is drinking to thirst optimum? Ann Nutr Metab 2010;57: :9-17.

33 Nuccio RP, Barnes KA, Carter JM, et al. Fluid balance in team sport athletes and the effect of Hypohydration on cognitive, technical, and physical performance. Sports Med 2017:47:1951-82.

34 Nilsson LH, Fürst P, Hultman E. Carbohydrate metabolism of the liver in normal man under varying dietary conditions. Scand J Clin Lab Invest 1973:32:331-7.

35 Williams C, Serratosa L. Nutrition on match day. J Sports Sci 2006;24:687-97.
36 Holway FE, Spriet LL. Sport-specific nutrition: practical strategies for team sports. J Sports Sci 2011:29 Suppl 1:S115-25.

37 Phillips SM, Sproule J, Turner AP. Carbohydrate ingestion during team games exercise: current knowledge and areas for future investigation. Sports Med 2011:41:559-85.

38 Russell M, Benton D, Kingsley M. Influence of carbohydrate supplementation on skill performance during a soccer match simulation. J Sci Med Sport 2012;15:348-54.

39 Briggs MA, Harper LD, McNamee G, et al. The effects of an increased calorie breakfast consumed prior to simulated match-play in Academy soccer players. Eur J Sport Sci 2017;17:858-66

40 American College of Sports Medicine, Sawka MN, Burke LM, et al. American College of sports medicine position stand. exercise and fluid replacement. Med Sci Sports Exerc 2007:39:377-90.

41 Baker LB, Nuccio RP, Jeukendrup AE. Acute effects of dietary constituents on motor skill and cognitive performance in athletes. Nutr Rev 2014;72:790-802.

42 Baker LB, Rollo I, Stein KW, et al. Acute effects of carbohydrate supplementation on intermittent sports performance. Nutrients 2015;7:5733-63.

43 Nicholas CW, Williams C, Lakomy HK, et al. Influence of ingesting a carbohydrateelectrolyte solution on endurance capacity during intermittent, high-intensity shuttle running. J Sports Sci 1995;13:283-90.

44 Russell M, Kingsley M. The efficacy of acute nutritional interventions on soccer skill performance. Sports Med 2014:44:957-70.

45 Rodriguez-Giustiniani P, Rollo I, Witard OC, et al. Ingesting a 12\% CarbohydrateElectrolyte Beverage Before Each Half of a Soccer Match Simulation Facilitates Retention of Passing Performance and Improves High-Intensity Running Capacity in Academy Players. Int J Sport Nutr Exerc Metab 2019;29:1-9.

46 Currell K, Conway S, Jeukendrup AE. Carbohydrate ingestion improves performance of a new reliable test of soccer performance. Int I Sport Nutr Exerc Metab 2009; 19:34-46.

47 Harper LD, Stevenson EJ, Rollo I, et al. The influence of a 12\% carbohydrateelectrolyte beverage on self-paced soccer-specific exercise performance. J Sci Med Sport 2017;20:1123-9.

48 Ali A, Williams C. Carbohydrate ingestion and soccer skill performance during prolonged intermittent exercise. J Sports Sci 2009;27:1499-508

49 Carter JM, Jeukendrup AE, Jones DA. The effect of carbohydrate mouth rinse on 1-H cycle time trial performance. Med Sci Sports Exerc 2004;36:2107-11.

50 Rollo I, Homewood G, Williams C, et al. The influence of carbohydrate mouth rinse on self-selected intermittent running performance. Int J Sport Nutr Exerc Metab 2015:25:550-8

51 Dorling JL, Earnest CP. Effect of carbohydrate mouth rinsing on multiple sprint performance. J Int Soc Sports Nutr 2013;10:41.

52 Duffield R, McCall A, Coutts AJ, et al. Hydration, sweat and thermoregulatory responses to professional football training in the heat. J Sports $\mathrm{SCi}$ 2012:30:957-65.

53 Baker LB, Barnes KA, Anderson ML, et al. Normative data for regional sweat sodium concentration and whole-body sweating rate in athletes. J Sports $\mathrm{SC}$ 2016:34:358-68.

54 Maughan RJ, Shirreffs SM, Merson SJ, et al. Fluid and electrolyte balance in elite male football (soccer) players training in a cool environment. J Sports SC 2005:23:73-9.

55 Da Silva RP, Mündel T, Natali AJ, et al. Pre-game hydration status, sweat loss, and fluid intake in elite Brazilian young male soccer players during competition. J Sports Sci 2012:30:37-42.

56 Horowitz M. Heat acclimation, epigenetics, and cytoprotection memory. Compr Physiol 2014;4:199-230.

57 Kilding AE, Tunstall H, Wraith $E$, et al. Sweat rate and sweat electrolyte composition in international female soccer players during game specific training. Int J Sports Med 2009;30:443-7

58 González-Alonso J, Mora-Rodríguez R, Below PR, et al. Dehydration reduces cardiac output and increases systemic and cutaneous vascular resistance during exercise. J Appl Physiol 1995;79:1487-96.

59 Ganio MS, Armstrong LE, Casa DJ, et al. Mild dehydration impairs cognitive performance and mood of men. Br J Nutr 2011;106:1535-43.

60 Mohr M, Krustrup P. Heat stress impairs repeated jump ability after competitive elite soccer games. J Strength Cond Res 2013;27:683-9.

61 McGregor SJ, Nicholas CW, Lakomy HK, et al. The influence of intermittent highintensity shuttle running and fluid ingestion on the performance of a soccer skill. $J$ Sports Sci 1999;17:895-903.

62 McDermott BP, Anderson SA, Armstrong LE, et al. National athletic trainers' association position statement: fluid replacement for the physically active. J Athl Train 2017:52:877-95.

63 Nédélec M, McCall A, Carling C, et al. Recovery in soccer : part ii-recovery strategies. Sports Med 2013;43:9-22.

64 Burke LM, van Loon LJC, Hawley JA. Postexercise muscle glycogen resynthesis in humans. J App/ Physiol 2017;122:1055-67.

65 Maughan RJ, Leiper JB, Shirreffs SM. Restoration of fluid balance after exerciseinduced dehydration: effects of food and fluid intake. Eur J Appl Physiol Occup Physiol 1996;73:317-25 
66 Anderson L, Naughton RJ, Close GL, et al. Daily distribution of macronutrient intakes of professional soccer players from the English premier League. Int I Sport Nutr Exerc Metab 2017;27:491-8.

67 Costill DL, Pascoe DD, Fink WJ, et al. Impaired muscle glycogen resynthesis after eccentric exercise. J Appl Physio/ 1990;69:46-50.

68 Doyle JA, Sherman WM, Strauss RL. Effects of eccentric and concentric exercise on muscle glycogen replenishment. J App/ Physiol 1993;74:1848-55.

69 Widrick JJ, Costill DL, McConell GK, et al. Time course of glycogen accumulation after eccentric exercise. J Appl Physiol 1992;72:1999-2004.

70 Koopman R, Saris WHM, Wagenmakers AJM, et al. Nutritional interventions to promote post-exercise muscle protein synthesis. Sports Med 2007;37:895-906

71 Morton RW, McGlory C, Phillips SM. Nutritional interventions to augment resistance training-induced skeletal muscle hypertrophy. Front Physiol 2015;6:245.

72 van Loon LJC. Role of dietary protein in post-exercise muscle reconditioning. Nestle Nutr Inst Workshop Ser 2013:75:73-83.

73 Trommelen J, van Loon LJC. Pre-Sleep protein ingestion to improve the skeletal muscle adaptive response to exercise training. Nutrients 2016;8:763.

74 Pasiakos SM, Lieberman HR, McLellan TM. Effects of protein supplements on muscle damage, soreness and recovery of muscle function and physical performance: a systematic review. Sports Med 2014;44:655-70.

75 Jackman SR, Witard OC, Jeukendrup AE, et al. Branched-Chain amino acid ingestion can ameliorate soreness from eccentric exercise. Med Sci Sports Exerc 2010;42:962-70.

76 Bell PG, Walshe IH, Davison GW, et al. Montmorency cherries reduce the oxidative stress and inflammatory responses to repeated days high-intensity stochastic cycling. Nutrients 2014:6:829-43.

77 Vitale KC, Hueglin S, Broad E. Tart cherry juice in athletes: a literature review and commentary. Curr Sports Med Rep 2017:16:230-9.

78 Abbott W, Brashill C, Brett A, et al. Tart cherry juice: no effect on muscle function loss or muscle soreness in professional soccer players after a match. Int J Sports Physiol Perform 2019:1-21.

79 Peternelj T-T, Coombes JS. Antioxidant supplementation during exercise training: beneficial or detrimental? Sports Med 2011:41:1043-69.

80 Barnes MJ. Alcohol: impact on sports performance and recovery in male athletes. Sports Med 2014:44:909-19.

81 Parr EB, Camera DM, Areta JL, et al. Alcohol ingestion impairs maximal post-exercise rates of myofibrillar protein synthesis following a single bout of concurrent training. PLoS One 2014;9:e88384

82 Hobson RM, Maughan RJ. Hydration status and the diuretic action of a small dose of alcohol. Alcohol Alcohol 2010;45:366-73.

83 Prentice C, Stannard SR, Barnes MJ. Effects of heavy episodic drinking on physical performance in club level rugby union players. J Sci Med Sport 2015;18:268-71.

84 Afshar M, Richards S, Mann D, et al. Acute immunomodulatory effects of binge alcohol ingestion. Alcohol 2015;49:57-64.

85 Reilly TT. A motion analysis of work rate in different positional roles in professional football match play. Journal of Human Movement Studies 1976;2:87-97.

86 Russell M, Sparkes W, Northeast J, et al. Changes in acceleration and deceleration capacity throughout professional soccer Match-Play. J Strength Cond Res 2016;30:2839-44.

87 Akenhead R, Harley JA, Tweddle SP. Examining the external training load of an English premier League football team with special reference to acceleration. $J$ Strength Cond Res 2016;30:2424-32.

88 Anderson L, Orme P, Di Michele R, et al. Quantification of Seasonal-Long physical load in soccer players with different starting status from the English premier League: implications for maintaining squad physical fitness. Int I Sports Physiol Perform 2016;11:1038-46.

89 Malone JJ, Di Michele R, Morgans R, et al. Seasonal training-load quantification in elite English premier League soccer players. Int I Sports Physiol Perform 2015;10:489-97.

90 Bradley PS, Sheldon W, Wooster B, et al. High-Intensity running in English FA premier League soccer matches. J Sports Sci 2009:27:159-68.

91 Di Salvo V, Baron R, González-Haro C, et al. Sprinting analysis of elite soccer players during European champions League and UEFA cup matches. J Sports Sci 2010;28:1489-94.

92 Morgans R, Orme P, Anderson L, et al. An intensive winter fixture schedule induces a transient fall in salivary IgA in English premier League soccer players. Res Sports Med 2014;22:346-54.

93 Milsom J, Naughton R, O'Boyle A, et al. Body composition assessment of English premier League soccer players: a comparative DXA analysis of first team, U21 and U18 squads. J Sports Sci 2015;33:1799-806.

94 Milsom J, Barreira P, Burgess DJ, et al. Case study: Muscle atrophy and hypertrophy in a premier league soccer player during rehabilitation from ACL injury. Int I Sport Nutr Exerc Metab 2014;24): :543-52.

95 Enright K, Morton J, Iga J, et al. Implementing concurrent-training and nutritional strategies in professional football: a complex challenge for coaches and practitioners. Science and Medicine in Football 2017;1:65-73.

96 Enright $\mathrm{K}$, Morton J, Iga J, et al. The effect of concurrent training organisation in youth elite soccer players. Eur J Appl Physiol 2015;115:2367-81.
97 Jeong T-S, Bartlett JD, Joo C-H, et al. Acute simulated soccer-specific training increases PGC- $1 \alpha$ mRNA expression in human skeletal muscle. J Sports Sci 2015;33:1493-503.

98 Anderson L, Close GL, Morgans R, et al. Assessment of energy expenditure of a professional Goalkeeper from the English premier League using the doubly labeled water method. Int J Sports Physiol Perform 2019:14:681-4.

99 Gunnarsson TP, Bendiksen M, Bischoff R, et al. Effect of whey protein- and carbohydrate-enriched diet on glycogen resynthesis during the first $48 \mathrm{H}$ after a soccer game. Scand J Med Sci Sports 2013;23:508-15.

100 Authority EFS. Scientific opinion on dietary reference values for protein. Available: http://www.efsa.europa.eu/sites/default/files/consultation/110712\%2C0.pdf [Accessed 24 Sep 2019].

101 Morton RW, Murphy KT, McKellar SR, et al. A systematic review, meta-analysis and meta-regression of the effect of protein supplementation on resistance training induced gains in muscle mass and strength in healthy adults. Br J Sports Med 2018;52:376-84

102 Phillips SM, Fulgoni VL, Heaney RP, et al. Commonly consumed protein foods contribute to nutrient intake, diet quality, and nutrient adequacy. Am J Clin Nutr 2015;101:1346S-52.

103 Maughan RJ. Energy and macronutrient intakes of professional football (soccer) players. Br J Sports Med 1997;31:45-7

104 Bettonviel A EO, Brinkmans N YJ, Russcher K, et al. Nutritional status and daytime pattern of protein intake on match, Post-Match, rest and training days in senior professional and youth elite soccer players. Int I Sport Nutr Exerc Metab 2016;26:285-93.

105 Phillips SM. The impact of protein quality on the promotion of resistance exerciseinduced changes in muscle mass. Nutr Metab 2016;13:64.

106 Snijders T, Res PT, Smeets JSJ, et al. Protein ingestion before sleep increases muscle mass and strength gains during prolonged Resistance-Type exercise training in healthy young men. J Nutr 2015;145:1178-84.

107 Trommelen J, Kouw IWK, Holwerda AM, et al. Presleep dietary protein-derived amino acids are incorporated in myofibrillar protein during postexercise overnight recovery. Am J Physiol Endocrinol Metab 2018;314:E457-67.

108 Longland TM, Oikawa SY, Mitchell CJ, et al. Higher compared with lower dietary protein during an energy deficit combined with intense exercise promotes greater lean mass gain and fat mass loss: a randomized trial. Am J Clin Nutr 2016:103:738-46.

109 Murphy $\mathrm{CH}$, Hector AJ, Phillips SM. Considerations for protein intake in managing weight loss in athletes. Eur J Sport Sci 2015:15:21-8.

110 Wall BT, Morton JP, van Loon LJC. Strategies to maintain skeletal muscle mass in the injured athlete: nutritional considerations and exercise mimetics. Eur J Sport SC 2015; 15:53-62.

111 Micronutrients, I.o.M.U.P.o. Dietary reference intakes for vitamin A, vitamin K, arsenic, boron, chromium, copper, iodine, iron, manganese, molybdenum, nickel, silicon, vanadium, and zinc. Washington DC: National Academies Press (US), 2001.

112 Volek JS, Noakes T, Phinney SD. Rethinking fat as a fuel for endurance exercise. Eur J Sport Sci 2015;15:13-20.

113 Burke LM, Ross ML, Garvican-Lewis LA, et al. Low carbohydrate, high fat diet impairs exercise economy and negates the performance benefit from intensified training in elite race walkers. J Physiol 2017:595:2785-807.

114 Owens DJ, Sharples AP, Polydorou I, et al. A systems-based investigation into vitamin $D$ and skeletal muscle repair, regeneration, and hypertrophy. Am J Physiol Endocrinol Metab 2015:309:E1019-31.

115 He C-S, Handzlik M, Fraser WD, et al. Influence of vitamin D status on respiratory infection incidence and immune function during 4 months of winter training in endurance sport athletes. Exerc Immunol Rev 2013;19:86-101.

116 Owens DJ, Allison R, Close GL. Vitamin D and the athlete: current perspectives and new challenges. Sports Med 2018;48:3-16

117 Close GL, Russell J, Cobley JN, et al. Assessment of vitamin D concentration in non-supplemented professional athletes and healthy adults during the winter months in the UK: implications for skeletal muscle function. J Sports SCi 2013:31:344-53.

118 Morton JP, Iqbal Z, Drust B, et al. Seasonal variation in vitamin D status in professional soccer players of the English premier League. App/ Physiol Nutr Metab 2012;37:798-802.

119 Clark M, Reed DB, Crouse SF, et al. Pre- and post-season dietary intake, body composition, and performance indices of NCAA division I female soccer players. Int $\mathrm{J}$ Sport Nutr Exerc Metab 2003;13:303-19.

120 Gibson JC, Stuart-Hill L, Martin S, et al. Nutrition status of junior elite Canadian female soccer athletes. Int I Sport Nutr Exerc Metab 2011:21:507-14.

121 Vieth R, Bischoff-Ferrari H, Boucher BJ, et al. The urgent need to recommend an intake of vitamin D that is effective. Am J Clin Nutr 2007:85:649-50.

122 Owens DJ, Tang JCY, Bradley WJ, et al. Efficacy of high-dose vitamin D supplements for elite athletes. Med Sci Sports Exerc 2017:49:349-56.

123 Beard J, Tobin B. Iron status and exercise. Am J Clin Nutr 2000;72:594S-7.

124 McClung JP, Gaffney-Stomberg E, Lee JJ. Female athletes: a population at risk of vitamin and mineral deficiencies affecting health and performance. J Trace Elem Med Biol 2014;28:388-92. 
125 Woodson RD, Wills RE, Lenfant C. Effect of acute and established anemia on 02 transport at rest, submaximal and maximal work. J Appl Physiol Respir Environ Exerc Physiol 1978;44:36-43.

126 Bruinvels $\mathrm{G}$, Burden $\mathrm{R}$, Brown $\mathrm{N}$, et al. The prevalence and impact of heavy menstrual bleeding (menorrhagia) in elite and Non-Elite athletes. PLoS One 2016;11:e0149881.

127 Pedlar CR, Brugnara C, Bruinvels G, et al. Iron balance and iron supplementation for the female athlete: a practical approach. Eur J Sport Sci 2018;18:295-305.

$128 \operatorname{Sim}$ M, Garvican-Lewis LA, Cox GR, et al. Iron considerations for the athlete: a narrative review. Eur J App/ Physiol 2019;119:1463-78.

129 Clement DB, Sawchuk LL. Iron status and sports performance. Sports Medicine 1984:1:65-74.

130 Knovich MA, Storey JA, Coffman LG, et al. Ferritin for the clinician. Blood Rev 2009;23:95-104.

131 Shaskey DJ, Green GA. Sports haematology. Sports Med 2000;29:27-38.

132 Sundgot-Borgen J, Torstveit MK. The female football player, disordered eating, menstrual function and bone health. Br J Sports Med 2007;41 Suppl 1:i68-72.

133 Kitchin B. Nutrition counseling for patients with osteoporosis: a personal approach. $J$ Clin Densitom 2013;16:426-31.

134 Barry DW, Hansen KC, van Pelt RE, et al. Acute calcium ingestion attenuates exercise-induced disruption of calcium homeostasis. Med Sci Sports Exerc 2011:43:617-23.

135 Barry DW, Kohrt WM. Acute effects of 2 hours of moderate-intensity cycling on serum parathyroid hormone and calcium. Calcif Tissue Int 2007;80:359-65.

136 Haakonssen EC, Ross ML, Knight EJ, et al. The effects of a calcium-rich pre-exercise meal on biomarkers of calcium homeostasis in competitive female cyclists: a randomised crossover trial. PLoS One 2015;10:e0123302.

137 Foley KF, Boccuzzi L. Urine calcium: laboratory measurement and clinical utility. Lab Med 2010;41:683-6.

138 Pollock N, Chakraverty R, Taylor I, et al. An 8-year Analysis of Magnesium Status in Elite International Track \& Field Athletes. J Am Coll Nutr 2020;39:443-9.

139 Schwellnus M, Soligard T, Alonso J-M, et al. How much is too much? (Part 2) International Olympic Committee consensus statement on load in sport and risk of illness. Br J Sports Med 2016;50:1043-52.

140 Walsh NP. Recommendations to maintain immune health in athletes. Eur J Sport Sc 2018;18:820-31

141 Biørneboe J, Kristenson $\mathrm{K}$, Waldén $\mathrm{M}$, et al. Role of illness in male professional football: not a major contributor to time loss. Br J Sports Med 2016;50:699-702.

142 Drew MK, Vlahovich N, Hughes D, et al. A multifactorial evaluation of illness risk factors in athletes preparing for the summer Olympic Games. J Sci Med Sport 2017:20:745-50.

143 Gabbett TJ, Whyte DG, Hartwig TB, et al. The relationship between workloads, physical performance, injury and illness in adolescent male football players. Sports Med 2014:44:989-1003.

144 Needleman I, Ashley P, Meehan L, et al. Poor oral health including active caries in 187 UK professional male football players: clinical dental examination performed by dentists. Br J Sports Med 2016;50:41-4

145 Bermon S, Castell LM, Calder PC, et al. Consensus statement immunonutrition and exercise. Exerc Immunol Rev 2017;23:8-50.

146 Gleeson M. Immunological aspects of sport nutrition. Immunol Cell Biol 2016;94:117-23.

147 Wu G. Dietary protein intake and human health. Food Funct 2016;7:1251-65.

148 Witard OC, Turner JE, Jackman SR, et al. High dietary protein restores overreaching induced impairments in leukocyte trafficking and reduces the incidence of upper respiratory tract infection in elite cyclists. Brain Behav Immun 2014;39:211-9.

149 Singh M, Das RR. Zinc for the common cold. Cochrane Database Syst Rev 2013:6:CD001364.

150 Nieman DC, Henson DA, Austin MD, et al. Upper respiratory tract infection is reduced in physically fit and active adults. Br J Sports Med 2011;45:987-92.

151 Nieman DC, Henson DA, Gross SJ, et al. Quercetin reduces illness but not immune perturbations after intensive exercise. Med Sci Sports Exerc 2007:39:1561-9.

152 Somerville VS, Braakhuis AJ, Hopkins WG. Effect of flavonoids on upper respiratory tract infections and immune function: a systematic review and meta-analysis. Adv Nutr 2016:7:488-97.

153 Scherr J, Nieman DC, Schuster T, et al. Nonalcoholic beer reduces inflammation and incidence of respiratory tract illness. Med Sci Sports Exerc 2012;44:18-26.

154 Pyne DB, West NP, Cox AJ, et al. Probiotics supplementation for athletes - clinical and physiological effects. Eur J Sport Sci 2015;15:63-72.

155 Hao Q, Dong BR, Wu T. Probiotics for preventing acute upper respiratory tract infections. Cochrane Database Syst Rev 2015;2:CD006895.

156 Suarez-Arrones L, Lara-Lopez P, Maldonado R, et al. The effects of detraining and retraining periods on fat-mass and fat-free mass in elite male soccer players. Peer 2019;7:e7466

157 Silva JR, Brito J, Akenhead R, et al. The transition period in soccer: a window of opportunity. Sports Med 2016;46:305-13.

158 Sutton L WJ, Scott M, Reilly T. Body composition of international-and club level professional soccer players measured by dual-energy $x$-ray absorptiometry (DXA).. In: Reilly, G TA, ed. Contemporary Sport, Leisure and Ergonomics. Routledge, 2008
159 Anderson L, Close GL, Konopinski M, et al. Case study: muscle atrophy, hypertrophy, and energy expenditure of a premier League soccer player during rehabilitation from anterior cruciate ligament injury. Int J Sport Nutr Exerc Metab 2019;29:559-66.

160 Carling C, Orhant E. Variation in body composition in professional soccer players: interseasonal and intraseasonal changes and the effects of exposure time and player position. J Strength Cond Res 2010:24:1332-9.

161 Hind K, Slater G, Oldroyd B, et al. Interpretation of dual-energy X-ray Absorptiometry-Derived body composition change in athletes: a review and recommendations for best practice. J Clin Densitom 2018;21:429-43.

162 Thurlow S, Oldroyd B, Hind K. Effect of hand positioning on DXA total and regional bone and body composition parameters, precision error, and least significant change. J Clin Densitom 2018;21:375-82

163 Mendes AP CP, Teixeira VHvan Dijk CN NP, Cohen M, DELLA Villa S, et al, eds. Nutritional guidelines for football players, in injuries and health problems in football: what everyone should know. Springer Berlin Heidelberg, 2017: 595-606.

164 Sutton L, Stewart A. Body composition in sport, exercise and health. Abingdon: Routledge, 2012.

165 Bilsborough JC, Greenway K, Opar D, et al. The accuracy and precision of DXA for assessing body composition in team sport athletes. J Sports Sci 2014;32:1821-8.

166 Nuñez FJ, Munguia-Izquierdo D, Petri C, et al. Field methods to estimate fat-free mass in international soccer players. Int J Sports Med 2019:40:619-24.

167 Núñez FJ, Munguía-Izquierdo D, Suárez-Arrones L. Validity of field methods to estimate fat-free mass changes throughout the season in elite youth soccer players. Front Physiol 2020;11:16

168 Avlonitou E, Georgiou E, Douskas G, et al. Estimation of body composition in competitive swimmers by means of three different techniques. Int I Sports Med 1997; 18:363-8

169 Esco MR, Olson MS, Williford HN, et al. The accuracy of hand-to-hand bioelectrical impedance analysis in predicting body composition in college-age female athletes. J Strength Cond Res 2011;25:1040-5.

170 Stewart AD, Hannan WJ. Prediction of fat and fat-free mass in male athletes using dual X-ray absorptiometry as the reference method. J Sports Sci 2000;18:263-74.

171 Clark RR, Sullivan JC, Bartok CJ, et al. DXA provides a valid minimum weight in wrestlers. Med Sci Sports Exerc 2007;39:2069-75

172 Wang Z, Heymsfield SB, Chen Z, et al. Estimation of percentage body fat by dualenergy $\mathrm{x}$-ray absorptiometry: evaluation by in vivo human elemental composition. Phys Med Biol 2010:55:2619-35.

173 Leão C, Simões M, Silva B, et al. Body composition evaluation issue among young elite football players: DXA assessment. Sports 2017:5:17

174 Tinsley GM, Morales E, Forsse JS, et al. Impact of acute dietary manipulations on DXA and BIA body composition estimates. Med Sci Sports Exerc 2017:49:823-32

175 Ackland TR, Lohman TG, Sundgot-Borgen J, et al. Current status of body composition assessment in sport: review and position statement on behalf of the AD hoc research Working group on body composition health and performance, under the auspices of the I.O.C. Medical Commission. Sports Med 2012:42:227-49.

176 Milanese C, Cavedon V, Corradini G, et al. Seasonal DXA-measured body composition changes in professional male soccer players. J Sports $\mathrm{SCi}$ 2015:33:1219-28

177 Devlin BL, Kingsley M, Leveritt MD, et al. Seasonal changes in soccer players' body composition and dietary intake practices. J Strength Cond Res 2017;31:3319-26.

178 Nattiv A, Loucks AB, Manore MM, et al. American College of sports medicine position stand. the female athlete triad. Med Sci Sports Exerc 2007;39:1867-82.

179 Mountjoy M, Sundgot-Borgen J, Burke L, et al. International Olympic Committee (IOC) consensus statement on relative energy deficiency in sport (RED-S): 2018 update. Int J Sport Nutr Exerc Metab 2018;28:316-31.

180 Sundgot-Borgen J, Meyer NL, Lohman TG, et al. How to minimise the health risks to athletes who compete in weight-sensitive sports review and position statement on behalf of the $A D$ hoc research Working group on body composition, health and performance, under the auspices of the IOC medical Commission. Br J Sports Med 2013:47:1012-22.

181 Reed JL, De Souza MJ, Kindler JM, et al. Nutritional practices associated with low energy availability in division I female soccer players. J Sports $\mathrm{SC}$ 2014:32:1499-509.

182 Burke LM, Lundy B, Fahrenholtz IL, et al. Pitfalls of conducting and interpreting estimates of energy availability in free-living athletes. Int J Sport Nutr Exerc Metab 2018;28:350-63.

183 Prather $\mathrm{H}$, Hunt D, McKeon K, et al. Are elite female soccer athletes at risk for disordered eating attitudes, menstrual dysfunction, and stress fractures? PM\&R 2016:8:208-13.

184 Heikura IA, Uusitalo ALT, Stellingwerff T, et al. Low energy availability is difficult to assess but outcomes have large impact on bone injury rates in elite distance athletes. Int J Sport Nutr Exerc Metab 2018;28:403-11.

185 Garvican LA, Hammond K, Varley MC, et al. Lower running performance and exacerbated fatigue in soccer played at 1600 M. Int J Sports Physiol Perform 2014;9:397-404.

186 Mohr M, Nybo L, Grantham J, et al. Physiological responses and physical performance during football in the heat. PLoS One 2012;7:e39202. 
187 Armstrong LE. Nutritional strategies for football: counteracting heat, cold, high altitude, and jet lag. J Sports Sci 2006;24:723-40.

188 Waterhouse J, Kao S, Edwards B, et al. Transient changes in the pattern of food intake following a simulated time-zone transition to the East across eight time zones. Chronobiol Int 2005;22:299-319.

189 Judelson DA, Maresh CM, Anderson JM, et al. Hydration and muscular performance: does fluid balance affect strength, power and high-intensity endurance? Sports Med 2007;37:907-21.

190 Galloway SD, Maughan RJ. Effects of ambient temperature on the capacity to perform prolonged cycle exercise in man. Med Sci Sports Exerc 1997;29:1240-9.

191 Maughan RJ, Otani H, Watson P. Influence of relative humidity on prolonged exercise capacity in a warm environment. Eur J Appl Physiol 2012;112:2313-21.

192 Otani H, Kaya M, Tamaki A, et al. Air velocity influences thermoregulation and endurance exercise capacity in the heat. Appl Physiol Nutr Metab 2018;43:131-8.

193 Otani H, Kaya M, Tamaki A, et al. Effects of solar radiation on endurance exercise capacity in a hot environment. Eur J Appl Physiol 2016;116:769-79.

194 Racinais S, Alonso JM, Coutts AJ, et al. Consensus recommendations on training and competing in the heat. Br J Sports Med 2015;49:1164-73.

195 Shirreffs SM, Sawka MN. Fluid and electrolyte needs for training, competition, and recovery. J Sports Sci 2011;29 Suppl 1:S39-46.

196 Burdon CA, Johnson NA, Chapman PG, et al. Influence of beverage temperature on Palatability and fluid ingestion during endurance exercise: a systematic review. Int J Sport Nutr Exerc Metab 2012.

197 Lee JKW, Shirreffs SM, Maughan RJ. Cold drink ingestion improves exercise endurance capacity in the heat. Med Sci Sports Exerc 2008;40:1637-44

198 Armstrong LE, Case DJ. Methods to evaluate electrolyte and water turnover of athletes. Athletic Training \& Sport Health Care 2009;4:169-79.

199 Gebhardt SEaT. Nutritive value of foods, 2002. Available: https://naldc.nal.usda.gov/ download/CAT11131126/PDF

200 Ganio MS, Armstrong LE, Kavouras SA. Hydration. In: Casa D, Stearns RL, eds. Hydration, in sport and physical activity in the heat: maximizing performance and safety. New York, NY: Springer Nature, 2018: 83-100.

201 Aughey RJ, Hammond K, Varley MC, et al. Soccer activity profile of altitude versus sea-level natives during acclimatisation to $3600 \mathrm{M}$ (ISA3600). Br J Sports Med 2013:47 Suppl 1:107-13.

202 Roberts AC, Butterfield GE, Cymerman A, et al. Acclimatization to 4,300-m altitude decreases reliance on fat as a substrate. J App/ Physiol 1996;81:1762-71.

203 Koehle MS, Cheng I, Sporer B. Canadian Academy of sport and exercise medicine position statement: athletes at high altitude. Clin J Sport Med 2014:24:120-7.

204 Gore CJ, Rodríguez FA, Truijens MJ, et al. Increased serum erythropoietin but not red cell production after 4 wk of intermittent hypobaric hypoxia (4,000-5,500 M). J Appl Physiol 2006;101:1386-93.

205 Gore CJ, McSharry PE, Hewitt AJ, et al. Preparation for football competition at moderate to high altitude. Scand I Med Sci Sports 2008;18 Suppl 1:85-95.

206 Fowler PM, Knez W, Crowcroft S, et al. Greater effect of East versus West travel on jet lag, sleep, and team sport performance. Med Sci Sports Exerc 2017;49:2548-61.

207 Fowler P, Duffield R, Howle K, et al. Effects of northbound long-haul international air travel on sleep quantity and subjective jet lag and wellness in professional Australian soccer players. Int I Sports Physiol Perform 2015;10:648-54.

208 Medical guidelines for air travel. aerospace Medical association, air transport medicine Committee, Alexandria, Va. Aviat Space Environ Med 1996;67:1-6.

209 Cardinali DP, Bortman GP, Liotta G, et al. A multifactorial approach employing melatonin to accelerate resynchronization of sleep-wake cycle after a 12 time-zone westerly transmeridian flight in elite soccer athletes. J Pineal Res 2002;32:41-6.

210 Piérard C, Beaumont M, Enslen M, et al. Resynchronization of hormonal rhythms after an eastbound flight in humans: effects of slow-release caffeine and melatonin. Eur J Appl Physiol 2001;85:144-50.

211 Halson SL, Burke LM, Pearce J. Nutrition for travel: from jet lag to catering. Int J Sport Nutr Exerc Metab 2019:29:228-35.

212 Poli LRaRB. Foreign players in football teams, 2016. Available: http://www.footballobservatory.com/lMG/pdf/mr12 eng.pdf [Accessed 12 Sep 2019].

213 Miller T. Mapping the global Muslim population: A report on the size and distribution of the world's Muslim population, 2009. Available: http://www.pewforum.org/ newassets/images/reports/Muslimpopulation/Muslimpopulation.pdf [Accessed 12 Aug 2017].

214 Abaïdia A-E, Daab W, Bouzid MA. Effects of Ramadan fasting on physical performance: a systematic review with meta-analysis. Sports Med 2020;50:1009-26.

215 Maughan RJ, Zerguini Y, Chalabi H, et al. Ramadan and football. J Sports Sci 2012;30 Suppl 1.

216 Maughan RJ, Zerguini Y, Chalabi H, et al. Achieving optimum sports performance during Ramadan: some practical recommendations. J Sports Sci 2012;30 Suppl 1:S109-17.

217 Schäfer T, Böhler E, Ruhdorfer S, et al. Epidemiology of food allergy/food intolerance in adults: associations with other manifestations of atopy. Allergy 2001;56:1172-9.

218 Lis DM, Kings D, Larson-Meyer DE. Dietary practices adopted by Track-and-Field athletes: gluten-free, low FODMAP, vegetarian, and fasting. Int I Sport Nutr Exerc Metab 2019;29:236-45.
219 Turnbull JL, Adams HN, Gorard DA. Review article: the diagnosis and management of food allergy and food intolerances. Aliment Pharmacol Ther 2015:41:3-25.

220 Lis DM, Stellingwerff T, Shing CM, et al. Exploring the popularity, experiences, and beliefs surrounding gluten-free diets in nonceliac athletes. Int I Sport Nutr Exerc Metab 2015;25:37-45

221 Lis D, Stellingwerff T, Kitic CM, et al. No effects of a short-term gluten-free diet on performance in Nonceliac athletes. Med Sci Sports Exerc 2015;47:2563-70.

222 Biesiekierski JR, Iven J. Non-coeliac gluten sensitivity: piecing the puzzle together. United European Gastroenterol J 2015;3:160-5.

223 Meyer N, Reguant-Closa A. "Eat as If You Could Save the Planet and Win!" Sustainability Integration into Nutrition for Exercise and Sport. Nutrients 2017:9:412.

224 Leahy EL, Tol, SJ S. An estimate of the number of vegetarians in the world. The Economic and Social Research Institute 2010;340.

225 Pelly FE, Burkhart SJ. Dietary regimens of athletes competing at the Delhi 2010 Commonwealth games. Int I Sport Nutr Exerc Metab 2014;24:28-36.

226 Melina V, Craig W, Levin S. Position of the Academy of nutrition and dietetics: vegetarian diets. J Acad Nutr Diet 2016;116:1970-80.

227 Craddock JC, Probst YC, Peoples GE. Vegetarian and omnivorous NutritionComparing physical performance. Int J Sport Nutr Exerc Metab 2016;26:212-20.

228 Guddat S, Fußhöller G, Geyer H, et al. Clenbuterol - regional food contamination a possible source for inadvertent doping in sports. Drug Test Anal 2012;4:534-8.

229 Thevis M, Schänzer W, Geyer H, et al. Traditional Chinese medicine and sports drug testing: identification of natural steroid administration in doping control urine samples resulting from MuSK (pod) extracts. Br I Sports Med 2013:47:109-14.

230 WADA. The World Anti-Doping Code 2015 with 2019 amendments, 2019. Available: https://www.wada-ama.org/en/what-we-do/the-code [Accessed 1 Aug 2019].

231 Garthe I, Maughan RJ. Athletes and supplements: prevalence and perspectives. Int J Sport Nutr Exerc Metab 2018;28:126-38.

232 Maughan RJ, Burke LM, Dvorak J, et al. IOC consensus statement: dietary supplements and the high-performance athlete. Int I Sport Nutr Exerc Metab 2018:28:104-25.

233 Aljaloud SO, Ibrahim SA. Use of dietary supplements among professional athletes in Saudi Arabia. J Nutr Metab 2013:2013:1-7.

234 Tscholl P, Junge A, Dvorak J. The use of medication and nutritional supplements during FIFA world CUPS 2002 and 2006. Br I Sports Med 2008:42:725-30

235 Mettler S, Zimmermann MB. Iron excess in recreational marathon runners. Eur J Clin Nutr 2010:64:490-4.

236 Sousa M, Fernandes MJ, Carvalho P, et al. Nutritional supplements use in highperformance athletes is related with lower nutritional inadequacy from food. I Sport Health Sci 2016:5:368-74.

237 Geyer H, Parr MK, Mareck U, et al. Analysis of non-hormonal nutritional supplements for anabolic-androgenic steroids - results of an international study. Int I Sports Med 2004;25:124-9.

238 HFL. Supplements and banned substance contamination: Offering and informed choice, 2007. Available: https://www.informed-sport.com/ [Accessed 16 Apr 2018].

239 Mathews NM. Prohibited contaminants in dietary supplements. Sports Health 2018:10:19-30

240 Cohen PA, Travis JC, Keizers PHJ, et al. Four experimental stimulants found in sports and weight loss supplements: 2-amino-6-methylheptane (octodrine), 1,4-dimethylamylamine (1,4-DMAA), 1,3-dimethylamylamine (1,3-DMAA) and 1,3-dimethylbutylamine (1,3-DMBA). Clin Toxicol 2018:56:421-6.

241 Geyer H, Braun H, Burke LM, et al. A-Z of nutritional supplements: dietary supplements, sports nutrition foods and ergogenic aids for health and performance-Part 22. Br J Sports Med 2011;45:752-4.

242 Geyer H. Adulterated nutritional supplements and unapproved pharmaceuticals as new sources of doping substances for fitness and recreational sports. In: Ahmadi $N$ LA, Göran S, eds. Doping and public health. London, UK: Routledge, 2016: 64-70.

243 Thevis M, Krug O, Piper T, et al. Solutions Advertised as erythropoiesis-stimulating products were found to contain undeclared cobalt and nickel species. Int I Sports Med 2016;37:82-4

244 Thevis M, Geyer L, Geyer H, et al. Adverse analytical findings with clenbuterol among U-17 soccer players attributed to food contamination issues. Drug Test Anal 2013:5:372-6.

245 Maughan RJ, Shirreffs SM, Vernec A. Making decisions about supplement use. Int Sport Nutr Exerc Metab 2018;28:212-9.

246 Curtis L. Nutritional research may be useful in treating tendon injuries. Nutrition 2016:32:617-9

247 Demling RH. Nutrition, anabolism, and the wound healing process: an overview. Eplasty 2009;9:e9.

248 Pasini E, Aquilani R, Dioguardi FS, et al. Hypercatabolic syndrome: molecular basis and effects of nutritional supplements with amino acids. Am J Cardiol 2008:101:S11-15.

249 Bell PG, McHugh MP, Stevenson E, et al. The role of cherries in exercise and health. Scand J Med Sci Sports 2014;24:477-90.

250 Lin E, Kotani JG, Lowry SF. Nutritional modulation of immunity and the inflammatory response. Nutrition 1998;14:545-50. 
251 Tipton KD. Nutritional support for exercise-induced injuries. Sports Med 2015;45 Suppl 1:93-104.

252 Wall BT, Snijders T, Senden JMG, et al. Disuse impairs the muscle protein synthetic response to protein ingestion in healthy men. J Clin Endocrinol Metab 2013;98:4872-81.

253 Rittweger J, Winwood K, Seynnes O, et al. Bone loss from the human distal tibia epiphysis during 24 days of unilateral lower limb suspension. J Physiol 2006;577:331-7.

254 de Boer MD, Maganaris CN, Seynnes OR, et al. Time course of muscular, neural and tendinous adaptations to 23 day unilateral lower-limb suspension in young men. J Physiol 2007;583:1079-91.

255 Dideriksen K, Boesen AP, Reitelseder S, et al. Tendon collagen synthesis declines with immobilization in elderly humans: no effect of anti-inflammatory medication. J Appl Physiol 2017;122:273-82.

256 Biolo G, Agostini F, Simunic B, et al. Positive energy balance is associated with accelerated muscle atrophy and increased erythrocyte glutathione turnover during 5 wk of bed rest. Am J Clin Nutr 2008;88:950-8.

257 Paddon-Jones D, Sheffield-Moore M, Urban RJ, et al. Essential amino acid and carbohydrate supplementation ameliorates muscle protein loss in humans during 28 days bedrest. J Clin Endocrinol Metab 2004;89:4351-8.

258 Stuart CA, Shangraw RE, Peters EJ, et al. Effect of dietary protein on bed-rest-related changes in whole-body-protein synthesis. Am I Clin Nutr 1990;52:509-14.

259 Rodríguez Rodríguez F, Delgado Ormeño A, Rivera Lobos P, et al. [Effects of B-alanine supplementation on wingate tests in university female footballers]. Nutr Hosp 2014;31:430-5.

260 Smith GI, Atherton P, Reeds DN, et al. Dietary omega-3 fatty acid supplementation increases the rate of muscle protein synthesis in older adults: a randomized controlled trial. Am J Clin Nutr 2011;93:402-12.

261 Deutz NEP, Pereira SL, Hays NP, et al. Effect of $\beta$-hydroxy- $\beta$-methylbutyrate (HMB) on lean body mass during 10 days of bed rest in older adults. Clin Nutr 2013;32:704-12

262 Adams CM, Ebert SM, Dyle MC. Use of mRNA expression signatures to discover small molecule inhibitors of skeletal muscle atrophy. Curr Opin Clin Nutr Metab Care 2015;18:263-8.

263 Babraj JA, Smith K, Cuthbertson DJR, et al. Human bone collagen synthesis is a rapid, nutritionally modulated process. J Bone Miner Res 2005;20:930-7.

264 Townsend R, Elliott-Sale KJ, Currell K, et al. The effect of postexercise carbohydrate and protein ingestion on bone metabolism. Med Sci Sports Exerc 2017:49:1209-18.

265 Farup J, Rahbek SK, Vendelbo MH, et al. Whey protein hydrolysate augments tendon and muscle hypertrophy independent of resistance exercise contraction mode. Scand J Med Sci Sports 2014;24:788-98.

266 Shaw G, Lee-Barthel A, Ross ML, et al. Vitamin C-enriched gelatin supplementation before intermittent activity augments collagen synthesis. Am J Clin Nutr 2017;105:136-43.

267 Ekstrand J, Krutsch W, Spreco A, et al. Time before return to play for the most common injuries in professional football: a 16-year follow-up of the UEFA elite Club injury study. Br I Sports Med 2020;54:421-6.

268 Castagna C, Abt G, D'Ottavio S. Physiological aspects of soccer refereeing performance and training. Sports Med 2007;37:625-46.

269 D'Ottavio S CC. Physiological aspects of soccer refereeing. London, UK: Routledge, 2002.

270 da Silva Al, Fernandes LC, Fernandez R. Energy expenditure and intensity of physical activity in soccer Referees during match-play. J Sports Sci Med 2008;7:327-34.

271 Weston M, Castagna C, Impellizzeri FM, et al. Science and medicine applied to soccer refereeing: an update. Sports Med 2012;42:615-31.

272 Stølen T, Chamari K, Castagna C, et al. Physiology of soccer: an update. Sports Med 2005;35:501-36.

273 Reilly T, Gregson W. Special populations: the referee and assistant referee. J Sports Sci 2006;24:795-801.

274 Schenk K, Bizzini M, Gatterer H. Exercise physiology and nutritional perspectives of elite soccer refereeing. Scand J Med Sci Sports 2018;28:782-93.

275 Riddell MC. The endocrine response and substrate utilization during exercise in children and adolescents. J Appl Physiol 2008;105:725-33.

276 Briggs MA, Cockburn E, Rumbold PLS, et al. Assessment of energy intake and energy expenditure of male adolescent Academy-Level soccer players during a competitive week. Nutrients 2015;7:8392-401.

277 Briggs MA, Rumbold PLS, Cockburn E, et al. Agreement between two methods of dietary data collection in male adolescent Academy-Level soccer players. Nutrients 2015;7:5948-60.

278 Ruiz F, Irazusta A, Gil S, et al. Nutritional intake in soccer players of different ages. J Sports Sci 2005;23:235-42.

279 Russell M, Pennock A. Dietary analysis of young professional soccer players for 1 week during the competitive season. J Strength Cond Res 2011;25:1816-23.

280 Braun $\mathrm{H}$, von Andrian-Werburg J, Schänzer W, et al. Nutrition status of young elite female German football players. Pediatr Exerc Sci 2018;30:157-67.

281 Martin L, Lambeth A, Scott D. Nutritional practices of national female soccer players: analysis and recommendations. J Sports Sci Med 2006;5:130-7.
282 Varley I, Hughes DC, Greeves JP, et al. Increased training volume improves bone density and cortical area in adolescent football players. Int I Sports Med 2017;38:341-6.

283 Hannon MP, Carney DJ, Floyd S, et al. Cross-Sectional comparison of body composition and resting metabolic rate in premier League Academy soccer players: implications for growth and maturation. J Sports Sci 2020;38:1326-34.

284 Hannon MP, Parker LJF, Carney DJ, et al. Energy requirements of male academy soccer players from the English Premier League. Medicine and Science in Sports and Exercise 2020;Online ahead of print.

285 Desbrow B, McCormack J, Burke LM, et al. Sports dietitians Australia position statement: sports nutrition for the adolescent athlete. Int I Sport Nutr Exerc Metab 2014:24:570-84.

286 Henderson B, Cook J, Kidgell DJ, et al. Game and training load differences in elite junior Australian football. J Sports Sci Med 2015;14:494-500.

287 Devlin BL, Leveritt MD, Kingsley M, et al. Dietary intake, body composition, and nutrition knowledge of Australian football and soccer players: implications for sports nutrition professionals in practice. Int I Sport Nutr Exerc Metab 2017:27:130-8

288 Naughton RJ, Drust B, O'Boyle A, et al. Daily distribution of carbohydrate, protein and fat intake in elite youth Academy soccer players over a 7-day training period. Int J Sport Nutr Exerc Metab 2016;26:473-80.

289 Timmons BW, Bar-Or O, Riddell MC. Influence of age and pubertal status on substrate utilization during exercise with and without carbohydrate intake in healthy boys. Appl Physiol Nutr Metab 2007;32:416-25.

290 Leites GT, Cunha GS, Chu L, et al. Energy substrate utilization with and without exogenous carbohydrate intake in boys and men exercising in the heat. J App/ Physiol 2016;121:1127-34

291 Gidding SS, Dennison BA, Birch LL, et al. Dietary recommendations for children and adolescents: a guide for practitioners: consensus statement from the American heart association. Circulation 2005;112:2061-75.

292 Sonneville KR, Gordon CM, Kocher MS, et al. Vitamin D, calcium, and dairy intakes and stress fractures among female adolescents. Arch Pediatr Adolesc Med 2012; 166:595-600.

293 Wilk B, Meyer F, Bar-Or O, et al. Mild to moderate hypohydration reduces boys' high-intensity cycling performance in the heat. Eur J App/ Physiol 2014;114:707-13.

294 Dougherty KA, Baker LB, Chow M, et al. Two percent dehydration impairs and six percent carbohydrate drink improves boys basketball skills. Med Sci Sports Exerc 2006;38:1650-8

295 Council on Sports Medicine and Fitness and Council on School Health, Bergeron MF, Devore C, et al. Policy statement-Climatic heat stress and exercising children and adolescents. Pediatrics 2011;128:p. e741-7.

296 Decher NR, Casa DJ, Yeargin SW, et al. Hydration status, knowledge, and behavior in youths at summer sports camps. Int I Sports Physiol Perform 2008;3:262-78.

297 Ersoy N, Ersoy G, Kutlu M. Assessment of hydration status of elite young male soccer players with different methods and new approach method of substitute urine strip. I Int Soc Sports Nutr 2016;13:34.

298 Meyer F VK, Timmons BW, Wilk B. Fluid balance and dehydration in the young athlete: assessment considerations and effects on health and performance. American Journal of Lifestyle Medicine 2012;6:489-501.

299 Herriman M, Fletcher L, Tchaconas A, et al. Dietary supplements and young teens: misinformation and access provided by Retailers. Pediatrics 2017; 139:e20161257.

300 Manore MM, Patton-Lopez MM, Meng Y, et al. Sport nutrition knowledge, behaviors and beliefs of high school soccer players. Nutrients 2017;9:350.

301 Gant N, Ali A, Foskett A. The influence of caffeine and carbohydrate coingestion on simulated soccer performance. Int I Sport Nutr Exerc Metab 2010;20:191-7

302 Kingsley M, Penas-Ruiz C, Terry C, et al. Effects of carbohydrate-hydration strategies on glucose metabolism, sprint performance and hydration during a soccer match simulation in recreational players. J Sci Med Sport 2014;17:239-43.

303 Burke LM. Caffeine and sports performance. Appl Physiol Nutr Metab 2008:33:1319-34.

304 Mielgo-Ayuso J, Calleja-Gonzalez J, Del Coso J, et al. Caffeine supplementation and physical performance, muscle damage and perception of fatigue in soccer players: a systematic review. Nutrients 2019;11:440.

305 Peeling P, Binnie MJ, Goods PSR, et al. Evidence-Based supplements for the enhancement of athletic performance. Int I Sport Nutr Exerc Metab 2018;28:178-87.

306 Maganaris CN, Maughan RJ. Creatine supplementation enhances maximum voluntary isometric force and endurance capacity in resistance trained men. Acta Physiol Scand 1998;163:279-87.

307 Rawson ES, Stec MJ, Frederickson SJ, et al. Low-Dose creatine supplementation enhances fatigue resistance in the absence of weight gain. Nutrition 2011;27:451-5 
308 Rawson ES PA. Mechanisms of muscular adaptations to creatine supplementation: review article. International Journal of Sports Medicine 2007:8:43-53.

309 Dolan E, Gualano B, Rawson ES. Beyond muscle: the effects of creatine supplementation on brain creatine, cognitive processing, and traumatic brain injury. Eur J Sport Sci 2019;19:1-14.

310 Cancela P, Ohanian C, Cuitiño E, et al. Creatine supplementation does not affect clinical health markers in football players. Br J Sports Med 2008;42:731-5

311 Harris RC, Söderlund K, Hultman E. Elevation of creatine in resting and exercised muscle of normal subjects by creatine supplementation. Clin Sci 1992;83:367-74.

312 Roberts PA, Fox J, Peirce N, et al. Creatine ingestion augments dietary carbohydrate mediated muscle glycogen supercompensation during the initial
$24 \mathrm{~h}$ of recovery following prolonged exhaustive exercise in humans. Amino Acids 2016;48:1831-42.

313 Kelly V. $\beta$-alanine: performance effects, usage and side effects. Br J Sports Med 2018;52:311-2

314 Harris RC, Tallon MJ, Dunnett M, et al. The absorption of orally supplied beta-alanine and its effect on muscle carnosine synthesis in human vastus lateralis. Amino Acids 2006:30:279-89.

315 Nyakayiru J, Jonvik KL, Trommelen J, et al. Beetroot juice supplementation improves high-intensity intermittent type exercise performance in trained soccer players. Nutrients 2017:9:314.

316 Jones AM. Dietary nitrate supplementation and exercise performance. Sports Med 2014:44:35-45.

$\underline{\underline{m}}$ 